\title{
Borsa İstanbul Konaklama Şirketlerinde Sürdürülebilirlik Faaliyetlerinin Analizi
}

\section{Analysis of Sustainability Actıvities in Borsa Istanbul Lodging Companies}

Doç.Dr. Erdinç KARADENIZ

Mersin Üniversitesi

Turizm Fakültesi

Mersin, Türkiye

E-posta: ekaradeniz@mersin.edu.tr
Buket Dilan UZPAK

Mersin Üniversitesi

Sosyal Bilimler Enstitüsü

Mersin, Türkiye

E-posta: buketdln@hotmail.com

\section{Öz}

$\mathrm{Bu}$ araştırmanın amacı Borsa İstanbul'da işlem gören konaklama şirketlerinin sürdürülebilirlik faaliyetleri ile bu faaliyetleri raporlama düzeylerini analiz etmek ve konaklama şirketlerinin eksikliklerinin veya varsa üstün taraflarının neler olduğunu saptamaktır. Bu amaçla 11 adet konaklama şirketinin 2017, 2018 ve 2019 yıllarına ait faaliyet raporları ekonomik, çevresel ve sosyal faktörler çerçevesinde içerik analizi ile incelenmiştir. Analiz sonucunda konaklama şirketlerinin sürdürülebilirlik faaliyetleri ve bu faaliyetleri raporlama düzeylerinin genel olarak yetersiz kaldığı belirlenmiştir. Konaklama şirketlerinin sürdürülebilirlik temelinde en önemli eksiklikleri ekonomik, çevresel ve sosyal unsurlara sınırlı düzeyde yer vermeleri, sürdürülebilirlik bilincinde olmamaları ve faaliyetlerini sürdürülebilirlik temelinde gerçekleştirmemeleri olarak saptanmıştır.

Anahtar Kelimeler: Sürdürülebilirlik, Sürdürülebilirlik Raporlaması, Konaklama Şirketleri, Borsa İstanbul.

\section{Abstract}

The purpose of this research is to analyze the sustainability activities, reporting levels and to determine the shortcomings or superiorities of Borsa Istanbul lodging companies. For this purpose, the annual reports of 11 lodging companies for the years 2017, 2018 and 2019 were analyzed by content analysis within the framework of economic, environmental and social factors. As a result of the analysis, it was determined that sustainability activities and reporting levels of lodging companies were generally insufficient. The most important deficiencies of lodging companies on the basis of sustainability are that they place limited economic, environmental and social factors, are not aware of sustainability and do not perform their activities on the basis of sustainability.

Key Words: Sustainability, Sustainability Reporting, Lodging Companies, Borsa İstanbul.

Bu çalışma, 2019 yııının Temmuz ayında Mersin Üniversitesi Sosyal Bilimler Enstitüsü Turizm İşletmeciliği A.B.D. bünyesinde tamamlanan "Halka Açık Konaklama Şirketlerinde Sürdürülebilirlik Uygulamaları: Borsa İstanbul Sürdürülebilirlik Endeksi'nde Yer Alan Şirketler Ille Karşılaştırmalı Bir Analiz" başlıklı yüksek lisans tezinden üretilmiştir. 


\section{Giriş}

Tarihsel süreç içerisinde insanlık, doğa ve çevre sürekli bir etkileşim içerisinde bulunmaktadır. Zamanla hızlı nüfus artışı, kentleşme ve sanayileşme gibi etkenlerin hız kazanması, çevre ile ilgili ciddi sorunların ortaya çıkmasına neden olmuştur. Bu etkenler, tarihsel süreç içerisinde doğal çevreye ciddi zararlar vermiş ve doğanın geri dönülemez hasarlar almasına neden olmuştur. Kentleşme ve sanayileşme gibi etkenler doğrultusunda doğal kaynakların hızla tükenmesi ve buna karşın insan ihtiyaçlarının sürekli artışı, sürdürülebilirlik kavramının önem kazanmasına etki etmiştir (Özmehmet, 2008).

Sürdürülebilirlik kavramının ortaya çıkışı, 1970'li yılların başından itibaren çevreyle ilgili sorunların şiddetlenmesine dayanmaktadır. Bu bağlamda sürdürülebilirlik kavramı ilk defa 1972 yılında, İsveç'te düzenlenen Birleşmiş Milletler Stockholm Konferansı'nda, gelişmiş ülkelerin küresel kalkınmalarının çevresel etkileri üzerine kaygıları ve gelişmekte olan ülkelerin ekonomik kalkınmalarında orta yol bulmada bir gereksinim olarak gündeme taşınmıştır (Borsa İstanbul, 2014). Dünya üzerinde hızla artan insan nüfusu, çevresel dengenin bozulmasına neden olmaktadır. Sürekli işlenen ve dikkatsizce kullanılan topraklar, zamanla çölleşmeye, göllerdeki su kalitesinin nitelikçe bozulmasına ve tarımsal dönüşüm sonucunda topraktaki organik maddelerin kaybolmasına neden olmaktadır. Ekosistemde sürdürülebilirliği sağlamak, özellikle günümüzde bu etkilerin şiddetini artırmasından dolayı oldukça önem kazanmaktadır (Chapin vd., 1996).

Sürdürülebilirlik çerçevesinde elde edilen kaynaklar incelendiğinde; genel itibariyle çevre ile ilgili konulara değinildiği gözlemlenmektedir. Ancak, bu kavramı çevre ile sınırlandırmak doğru bir yaklaşım değildir. Sürdürülebilirlik; çevresel etki, ekonomik göstergeler ve sosyal refah gibi unsurları içerisinde barındıran bir kavramdır (Finkbeinervd., 2010). Bu nedenle insanların ve devletlerin olduğu kadar şirketlerin de sürdürülebilirliğe önem vermeleri ve bu doğrultuda faaliyet göstermeleri gerekmektedir. Bu kapsamda şirketlerin çevre ile ilgili yıkımlara karşı duyarlı olmaları, üretim ve pazarlama aşamalarında yenilik çalışmalarına dikkat etmeleri ve diğer rakip şirketlerin gerisinde kalmamaları için sürdürülebilirlik faaliyetlerine önem vermeleri gerekmektedir. Dolayısıyla şirketler, hedef aldıkları değer maksimizasyonuna ulaşmak için faaliyet gösterirken; topluma katkı sağlamayı ve faaliyetlerinde çevreye, ekosisteme, insanlara ve en önemlisi geleceğe zarar vermemeyi göz ardı etmemelidir (Kuşat, 2012).

Dünyanın en hızlı büyüyen ve ekonomiye katkısı yüksek olan sektörlerinden biri olan turizm sektörü; çevreyi koruma, kültürel mirasa sahip çıkma, yoksulluğun azalması gibi birçok alanda ön plana çıkmaktadır. Turizm sektörü, doğru yönetilmesi halinde doğal ve kültürel mirası korumaya, bulunduğu toplumu sosyo-ekonomik olarak güçlendirmeye, ticari fırsatlar yaratmaya ve kültürler arası etkileşimin sağlanmasına büyük katkı sağlamaktadır (UNWTO, 2017). Bu bağlamda turizm, sürdürülebilir kalkınmada önemli bir rol üstlenmektedir. Turizm sektöründe sürdürülebilirliğin sağlanması sadece sektörün olumsuz etkilerini kontrol etmek ve yönetmek ile değil, aynı zamanda ekonomik, çevresel ve sosyal faktörlerin bir bütün olarak değerlendirilerek gerekli durumlarda önlemler alınmasıyla mümkündür (UNEP, 2005).

$\mathrm{Bu}$ araştırmanın amacı, Borsa İstanbul'da (BIST) pay senetleri işlem gören konaklama şirketlerinde sürdürülebilirlik faaliyetlerini inceleyerek bu faaliyetlerin raporlanma düzeylerini ortaya koymaktır. Bu amaçla BIST' de işlem gören 11 adet konaklama şirketinin 2017, 2018ve 2019 yıllarındaki sürdürülebilirlik faaliyetleri ve raporlamaları, içerik analizi yöntemiyle incelenmiştir. Belirlenen amaçlar doğrultusunda 
araştırma beş bölümden oluşmaktadır. Araştırmanın ilk bölümünde konuyla ilgili kuramsal kavram ve bilgiler sunulmuştur. İkinci bölümde konuyla ilgili literatür taramasının sonuçları paylaşımıştır. Üçüncü bölümde araştırmanın verileri ve analiz yöntemi açıklanmıştır. Dördüncü bölümde analiz sonucunda elde edilen bulgular sunulmuştur. Son bölümde ise genel bir değerlendirme yapılmış ve öneriler geliştirilmeye çalışılmıştır.

\section{Kuramsal Çerçeve}

Sürdürülebilirlik kavramının teorideki genel tanımlarına bakılığında, tanımların 1987 yılında yayınlanan Brundtland Raporu'nda yer alan tanım çerçevesinde şekillendiği görülmektedir. "Ortak Geleceğimiz" adlı raporda sürdürülebilirlik kavramı, "bugünün ihtiyaçlarını karşılamayı hedeflerken, gelecek nesillerin ihtiyaçlarını karşılamalarını göz ardı etmeyen faaliyetler bütünü" olarak tanımlanmıştır (Anand ve Sen, 2000: 2034). Bu açıdan bakıldığında sürdürülebilirlik; biyolojik, etik, sosyolojik ve ekonomi gibi alanlarda farklı şekillerde tanımlanabilmektedir. Biyolojik çerçevede bakıldığında sürdürülebilirlik; çeşitliliğin korunması ve devam ettirilmesinin sağlanması olarak ele alınırken; sosyolojik açıdan sürdürülebilirlik, sosyal düzenin ve adaletin sağlanması, adil bir yaşam, güvenlik, sağlık, yoksullukla mücadele kavramları ile karşımıza çıkmaktadır. Etik anlamda sürdürülebilirlik ise doğada bulunan kaynakların korumacı bir yaklaşım ile kullanılmasını ve devamlıı̆ı̆na dikkat edilmesini ifade etmektedir. En sık karşılaşılan yaklaşım olan ekonomik açıdan sürdürülebilirlik ise doğada var olan her türlü kaynağın, üretim ve tüketim faaliyetlerinde çevresel faktörleri de göz önünde bulundurarak uzun vadeli analizlerin gerçekleştirilmesi anlamına gelmektedir (Bayraktutan ve Uçak, 2011).

BIST Sürdürülebilirlik Endeksi Araştırma Metodolojisinde (2015:2)'de sürdürülebilirlik kavramının; doğal kaynakların kullanımı, enerji kullanımı, iklim değişikliği, biyoçeşitlilik, yenilenebilir enerji kaynaklarına daha çok önem verilmesi ve geri dönüşüm gibi çevre ile ilgili faktörlerin yanı sıra; şirketlerde yönetim kurulu yapısı, rüşvetle mücadele, insan hakları, üretim sürecinde malların tedarik zinciri, çalışanların sağlık ve güvenliğinin sağlanması gibi sosyal ve kurumsal yönetim ile ilgili faktörleri de kapsadığı ifade edilmektedir.

Kurumsal sürdürülebilirlik ise sürdürülebilirlik kavramının şirketler düzeyindeki ifadesi olarak kabul edilmektedir. Bir şirket, sürdürülebilirlik ile ilgili somut adımlarını, kurumsal yönetimin şeffaflık, adillik, hesap verilebilirlik ve sorumluluk ilkelerine bağlı̆ğı ile hayata geçirebilmektedir. Şirketlerin üretim aşamasında doğaya daha az zarar veren teknolojiler kullanıp, çevre bilincini şirketin öncelikleri haline getirmeleri oldukça önemlidir. BIST'in yayımladığı sürdürülebilirlik rehberinde sürdürülebilirlik üç boyut bağlamında vurgulanmaktadır. Şirketlerde doğru bir sürdürülebilirlik stratejisinin geliştirilebilmesi için, sürdürülebilirliğin ekonomik boyutunun yanı sıra çevresel ve sosyal boyutlarının zincir halinde bir arada ele alınıp bu doğrultuda stratejiler geliştirilmesi gerekmektedir (Borsa İstanbul, 2014).

Kurumsal yönetimin şeffaflık ilkesi gereğince şirketler tüm paydaşlarına finansal bilgilerini sunmak zorundadır. Bununla beraber şirketlerin finansal olmayan bilgilerini daha çok gönüllülük esasına bağlı olarak açık, net ve ulaşılabilir olarak sunmaları şirketlerin itibarları açısından oldukça önemlidir (Pamukçu, 2011). Sosyal sorumluluk veya sürdürülebilirlik raporları olarak da ifade edilebilen bu raporlarda, şirkete ait çevresel, ekonomik ve sosyal faaliyetler yer almaktadır (Başar ve Başar, 2006).

Çevresel raporlamaların ilk örnekleri 1980'lerin sonuna Gösterdikleri faaliyetlerde çevreye ve doğaya karşı duyarlı olan şirketler, 
sürdürülebilirlik ile ilgili raporlarını düzenlemeye ve geliştirmeye çalışmışlardır. Bu raporlar, sadece şirket açısından değil, paydaşlar açısından da son derece önem arz etmektedir (Yükçü ve Kaplanoğlu, 2016). Şirketler, sadece yatırımcılarını paydaşları olarak görmezler, yatırımcılara karşı sorumlulukları aynı şekilde toplum için de geçerlidir. Bu nedenle de sürdürülebilirlik raporlarında, şirket performansının sürdürülebilirlik açısından hem olumlu hem de olumsuz yönlerinin açık bir şekilde ifade edilmesi gerekmektedir (GRI G3, 2006).

Günümüzde birçok şirket, faaliyet raporlarında sürdürülebilirlik ile ilgili yaptıkları çalışmalara yer verirken, bazıları bu bilgileri kurumsal web siteleri aracılığı ile duyurmaktadır. Şirketlerin sağlıklı bir raporlama yapabilmeleri için sürdürülebilirlik konusunda danışmanlık hizmetleri sunan kuruluşlara yönelmeleri gerekmektedir. Raporların temelinde, şirketlerin finansal ve finansal olmayan verilerinin arasındaki bağlantının kurulması bulunmaktadır. Raporlama yapılırken şirketler uzun vadede hedefler belirlemekte ve bu doğrultuda yönetim ile ilgili stratejiler, sürdürülebilirlik stratejileri ve şirket faaliyetlerine en uygun iş planlarını geliştirmektedirler. Bu şekilde, şirketlerin karşılaşabilecekleri muhtemel kriz ve fırsat durumları önceden görülebilmektedir (Borsa İstanbul, 2014).

Sürdürülebilirlik raporlamasında önemli rol oynayan ve ABD merkezli 1997 yılında kurulan Küresel Raporlama Girişimi'nin (Global Reporting Initiative - GRI) temel amacı; büyüklüğü ve faaliyet alanı ne olursa olsun tüm şirketlerin sürdürülebilirlik raporlamalarında faydalanabilecekleri bir çerçeve oluşturmaktır. Sürdürülebilirlik raporlamasında öncü olarak kabul edilen GRI standartları, 1997 yılından bu yana birçok sektörde ve dünyanın birçok ülkesinde şirketler tarafından tercih edilmekte ve hatta dünyanın en büyük 250 şirketinin \%93'ü sürdürülebilirlik raporlarını GRI standartlarına göre hazırlamaktadırlar. GRI standartlarında şirketlerin sürdürülebilirlik faaliyetleri; ekonomik, çevresel ve sosyal olmak üzere üç ana kategori altında değerlendirilmektedir. Şirketler, oluşabilecek risk veya fırsatları öngörebilmek, finansal ve finansal olmayan performanslarını sergilemek, uzun vadede yönetim stratejisi ve politikası oluşturabilmek gibi amaçlarla sürdürülebilirlik raporlarını hazırlamaktadır (GRI G3, 2006).

GRI, 2013 yılında yayınladığı G4 kılavuzunda yer alan ekonomik kategoride, şirkete ait sermayenin tüm paydaşlar arasında dağılımı gösterilmektedir. Aynı zamanda bu kılavuzda şirketin genel ekonomik durumuna da yer verilmektedir. Ekonomi kategorisinin unsurlarından olan ekonomik refahtan, şirketin bünyesinde yer alan tüm çalışanların ve paydaşların ekonomik durumlarının ne denli etkilediğinin saptanmasında faydalanılır. Çevresel kategoride ise su, enerji, atıklar, biyolojik çeşitlilik, ürün ve hizmetler, tedarik zinciri gibi unsurlar değerlendirilmektedir. Sosyal kategoride; işgücü uygulamaları ve insana yaraşır iş, toplum, insan hakları uygulamaları ve ürün sorumluluğundan oluşmaktadır. Bu ana kategori başlığı altında, iş ve işçi hakları, insan hakları, istihdam kalitesi, ayrımcılık, zorla çalıştırma, rüşvet gibi durumlar ile ilgili gereklilikler, yaptırımlar ve şirket faaliyetleri yer almaktadır (GRI G4, 2013).

\subsection{Literatür}

Sürdürülebilirlik, sürdürülebilir kalkınma ve sürdürülebilirliğin raporlanması konuları altında yapılan literatür taraması neticesinde dünya genelinde ve Türkiye'de konu ile ilgili araştırmaların özellikle son yıllarda artmaya başladığı gözlemlenmiştir. Sürdürülebilirliğin genel kabul görmüş tanımı üzerine yoğunlaşan araştırmaların çoğunda dikkat çeken bir diğer unsur da genellikle çevre faktörüne değinilmiş 
olduğudur. Turizm sektöründeki sürdürülebilirlik ile ilgili araştırmaların ise sürdürülebilir turizm başlığı altında değerlendirildiği görülmüştür. Özellikle gerçekleştirilen araştırmalarda, sürdürülebilirlik kavramının başlarda kavramsal olarak tartışıldığı, ancak son yıllarda turizm şirketlerinin de sürdürülebilirlik raporlarına ağırlık vermesi ile araştırmaların raporlamalar üzerine yoğunlaştığı gözlemlenmiştir. Bu bölümde turizm sektörüne yönelik sürdürülebilirlikle ilgili gerçekleştirilen ve tarafımızca önemli bulunan araştırmalar sürdürülebilir turizme yönelik ve sürdürülebilirliğin raporlanmasına yönelik araştırmalar şeklinde özetlenmeye çalışılmaktadır.

\subsubsection{Sürdürülebilir Turizme Yönelik Literatür}

Sürdürülebilir turizme yönelik literatür incelendiğinde ilk çalışmaların teorik temelde gerçekleştirildiği saptanmıştır. Sürdürülebilir turizmin özellikle 1980'li yıllardan itibaren kendinden söz ettirdiğini belirten Liu(2003), teori bağlamında gerçekleştirmiş olduğu çalışmasında sürdürülebilirlik ve sürdürülebilir kalkınma çatısı altında bulunan sürdürülebilir turizme olan talebin artması ve bu talebin karşılanması sırasında turistik ürünün gelecek nesillere aktarılmasının göz ardı edildiğini ve bu durumun ilerleyen yıllarda sorunlar yaratabileceğini vurgulamıştır. Teorik çalışmaların yanı sıra özellikle son yıllarda sürdürülebilirliğin önemine, paydaşların bilgilendirilmesine ve raporlanmasına değinilen çalışmaların arttığı görülmektedir. Herremans ve diğerleri (2011) ile Guixa ve diğerlerinin (2018) gerçekleştirmiş oldukları çalışmalarda sürdürülebilirliğe verilen önem üzerinde durulmuştur. Herremans ve diğerleri (2011), Çin ve Hindistan'daki küresel turizm şirketlerinin sürdürülebilirliğe verdikleri önemi ve paydaşlarını bilgilendirme düzeylerini ortaya koymaya çalışmışlardır. Araştırma sonucunda hava yolu şirketleri ile taşımacılık şirketlerinin sorumluluklarını yerine getirdiği saptanmıştır. Kumarhane hizmeti sunan otellerin ise sıklıkla kurumsal web sitelerinde sürdürülebilirlik ile ilgili ifadelere yer verirken, herhangi bir rapor hazırlayıp sunmadıkları gözlemlenmiştir. Çalışmada ayrıca analiz kapsamında yer alan şirketlerin neredeyse tamamının kurumsal web sitelerinde sürdürülebilirlik ile ilgili ifadelere yer verdiğini ama çok azının bu bilgileri GRI ilkelerine dayandırarak titizlikle hazırlanmış bir rapor halinde sundukları belirlenmiştir. Guixa ve diğerleri (2018) ise dünya genelinde ilk 50 'de bulunan 18 uluslararası otel grubunun yayınladığı sürdürülebilirlik raporlarında özellikle paydaşlarına karşı duyarlılık düzeylerini kapsayıcılık, önemlilik ve cevap verme açısından ortaya koymaya çalışmışlardır. Bu bağlamda, kapsayıcılık çerçevesinde, paydaşları en çok kapsayan şirketin Eastern Crown olduğu, önemlilik açısından ise şirketlerin tamamı sürdürülebilirliğe önem verdiği belirlenmiştir. Sürdürülebilirlik uygulamalarında ise Hyatt ilk sırada yer alırken, Accor'un ise son sırada yer aldığı saptanmıştır. Son olarak elde edilen bulgular doğrultusunda paydaşlara cevap verilebilirlikte Wyndham ilk sırada yer almıştır.

\subsubsection{Sürdürülebilirlik Faaliyetlerinin Raporlanmasına Yönelik Literatür}

Sürdürülebilirlikle ilgili literatür incelendiğinde, sürdürülebilirlik faaliyetlerinin raporlanmasının önemle vurgulandığı ve bu bağlamda Küresel Raporlama Girişimi (GRI) ilkelerini dikkate alarak gerçekleştirilen çalışmaların da son yıllarda sıklıkla yer aldığı gözlemlenmiştir. Medrado ve Jackson (2015), Ekergil ve Göde (2017) ile Karadeniz ve Uzpak (2019), gerçekleştirmiş oldukları çalışmalarında GRI ilkelerinin ekonomik, çevresel ve sosyal boyutları bağlamında değerlendirmeler yapmışlardır. Bu bağlamda Medrado ve Jackson (2015), turizm şirketlerinin kurumsal sosyal sorumluluk açısından sürdürülebilirlik boyutlarını incelemişlerdir. Araştırmada otel, yiyecek - içecek ve cruise gemileri olmak üzere 3 kategoriden 14 şirket ele alınmıştır. Bu şirketlere ait incelenen raporlarda kılavuz olarak GRI ilkelerinin kullanıldığı saptanmıştır. Şirketlerin raporlamada su tüketimi, enerji tasarrufu ve atık yönetimi gibi konulara ağırlık 
verdikleri, en az yer verilen konuların ise ücretler, tazminat ve iş-yaşam dengesi olduğu ortaya konmuştur. Ayrıca, cruise ve yiyecek - içecek şirketlerinin sürdürülebilirliğin sosyal, ekonomik ve çevresel boyutlarından en fazla çevre ile ilgili olan kısmına ağırlık verdikleri saptanmıştır. Ekergil ve Göde (2017), GRI ilkelerini kullanarak turizm şirketlerinin sürdürülebilirlik faaliyetlerini inceledikleri araştırmalarında, 2014-2017 yılları arasında kurumsal web sitelerinde sürdürülebilirlik raporlarını yayınlamış 10 turizm şirketini ele almışlardır. Nitel araştırma yöntemlerinden olan içerik analizinin kullanıldığı araştırmada, turizm şirketlerinin bu raporları daha çok pazarlama aracı olarak kullandıkları gözlemlenmiştir. Raporlardaki içerikler; çevre performansı, ekonomik performans ve sosyal performans olarak üç sınıfa ayrılsa da incelenen şirketler içerisinde \%60,86 ile çevre performansının ilk sırada yer aldığı saptanmıştır. Araştırmada ayrıca şirketlerin yayınladıkları sürdürülebilirlik raporlarını, belli bir şablon üzerinden sınırlı ve istedikleri bilgi düzeyinde hazırladıkları belirlenmiştir. Karadeniz ve Uzpak (2019) ise 2017 yılında dünyada en yüksek marka değerine sahip olan otel zincirlerinden ilk 5 tanesinin göstermiş olduğu faaliyetleri sürdürülebilirlik bağlamında değerlendirdikleri çalışmalarında, şirketlerin kurumsal web siteleri, faaliyet ve sürdürülebilirlik raporlarını incelemişler ve sürdürülebilirlik raporlarını GRI ilkeleri çerçevesinde analiz etmişlerdir. İçerik analizi ile gerçekleştirilen araştırma sonucunda otel zincirlerinin sürdürülebilirliğin üç ana kolu olan ekonomik, çevresel ve sosyal faktörlerden ekonomik ve sosyal kategoriye ağırlık verdiği, çevre ile ilgili faaliyetlerini raporlamada ise yetersiz kaldıkları saptanmıştır.

Yukarıda özetlenmeye çalışılan literatür neticesinde son yıllarda konuyla ilgili olarak turizm sektörüne yönelik araştırmaların arttığı, ancak BIST' te pay senetleri işlem gören konaklama şirketlerinin sürdürülebilirlik faaliyetlerini ve bu faaliyetlerin raporlanma düzeyini inceleyen herhangi bir araştırmaya tarafımızca rastlanmamıştır. $\mathrm{Bu}$ açıdan araştırmanın BIST konaklama şirketlerinin sürdürülebilirlik faaliyetlerinin neler olduğu ve bu faaliyetlerin nasıl raporlandığının ve eksikliklerinin ortaya konması açısından literatüre katkı sağlayacağı düşünülmektedir.

\section{Yöntem}

Bu araştırmanın temel amacı; BIST'te pay senetleri işlem gören konaklama şirketlerinin sürdürülebilirlik bağlamında ne gibi faaliyetlerde bulundukları ve bu faaliyetleri nasıl raporladıklarını değerlendirmektir. Bununla beraber GRI (Küresel Raporlama Girişimi) standartları çerçevesinde BIST konaklama şirketlerinin gerçekleştirdiği sürdürülebilirlik faaliyetleri ve bu faaliyetlerin raporlanmasıyla ilgili eksikliklerinin veya varsa üstün taraflarının neler olduğu saptanmaya çalışılmıştır.

Belirlenen amaçlar doğrultusunda araştırmanın örneklemini; Borsa İstanbul'da pay senetleri işlem gören ve Kamuyu Aydınlatma Platformu'nda (KAP) Lokanta ve Oteller alt sektöründe yer alan 12 adet şirketten 11 'i oluşturmaktadır. Tablo 1'de BIST Lokanta ve Oteller alt sektöründe işlem gören ve analiz kapsamında incelemeye dahil edilen konaklama şirketlerinin isimleri verilmektedir. BIST'te işlem gören konaklama şirketlerinin seçilme sebebi, bu şirketlerin borsada işlem gören şirketler olmaları ve bu nedenle şirket faaliyet raporlarını ve bilgilerini kamuoyuyla paylaşma yükümlülüklerinin olmasıdır. Şirketler arasında yer alan Etiler Gıda ve Ticari Yatırımlar Sanayi ve Ticaret A.Ş., yiyecek-içecek (lokanta) alt sektöründe hizmet verdiğinden dolayı çalışma kapsamına dahil edilmemiştir. 
Tablo 1: Analiz Kapsamındaki Konaklama Şirketleri

\begin{tabular}{|l|}
\hline 1.Altın Yunus Çeşme Turistik Tesisler A.Ş. \\
\hline 2.Avrasya Petrol ve Turistik Tesisler A.Ş. \\
\hline 3.Kuştur Kuşadası Turizm Endüstrisi A.Ş. \\
\hline 4.Marmaris Altın Yunus Turistik Tesisler A.Ş. \\
\hline 5.Martı Otel Şirketleri A.Ş. \\
\hline 6.Merit Turizm Yatırım Ve İşletme A.Ş. \\
\hline 7.Metemtur Otelcilik Ve Turizm Şirketleri A.Ş. \\
\hline 8.Petrokent Turizm A.Ş. \\
\hline 9.Tek-Art İnşaat Ticaret Turizm Sanayi Ve Yatırımlar A.Ş. \\
\hline 10.Ulaşlar Turizm Yatırım ve Dayanıklı Tüketim MallarıA.Ş. \\
\hline 11.Utopya Turizm İnşaat İşletmecilik Ticaret A.Ş. \\
\hline
\end{tabular}

Analiz kapsamındaki şirketlerin sürdürülebilirlik faaliyetleri ve bu faaliyetlerin raporlanması, GRI standartları çerçevesinde ekonomik, sosyal ve çevresel faaliyetleri bağlamında değerlendirilmiştir. Değerlendirme bağlamında intiyaç duyulan verilerin; şirketlerin faaliyet raporlarından ve sürdürebilirlik raporlarından elde edilmesi öncelikle planlanmıştır. Ancak BIST konaklama şirketlerinin sürdürülebilirlik raporu yayımlamadıkları saptanmış ve ilgili veriler şirketlerin 2017, 2018 ve 2019 yıllarına ait faaliyet raporlarından doküman incelemesi yöntemi ile elde edilmiştir.

Doküman incelemesi, araştırma kapsamına giren konular ile ilgili bilgilerin yer aldığı yazılı kaynakların değerlendirilmesini kapsamaktadır. Yazılı ve görsel kaynaklar geçmiş ile ilgili araştırmacılara birçok bilgi sunmaktadır. Araştırma dahilinde bazı durumlarda gözlem ve görüşme olanaksız olabilmekte veya araştırmaya daha somut kaynaklar sunmak gerekebilmektedir. Bu gibi durumlarda, araştırmanın kapsamı dahilinde görsel materyal ve malzemeler araştırmaya dahil edilerek doküman incelemesi gerçekleştirilebilmektedir. Doküman incelemesi, tek başına bir araştırma yöntemi olduğu gibi, diğer araştırma yöntemlerinin kullanılmasında da veri toplama aracı olarak kullanılabilmektedir (Şimşek ve Yıldırım, 2000).

Araştırmada belirlenen hedefler doğrultusunda; şirketlere ait faaliyet raporları üzerinde içerik analizi uygulanmıştır. Araştırmada kullanılan içerik analizi; sözel ve sözel olmayan materyallerin iletmek istediği mesaj, anlam ve dilbilgisi açısından nesnel ve sistematik bir şekilde sınıflandırılmasını, sayılara dönüştürülmesini sağlayarak, bu bilgilerden çıkarımlarda bulunulmasını sağlayan bir yaklaşımdır (Tavşancıl ve Aslan, 2001). Gerçekleştirilen içerik analizi kapsamında 46 kod ve 3 uygun tema (ekonomik, çevresel ve sosyal) oluşturulmuştur.

\section{Bulgular}

Araştırmanın bu bölümünde, BIST' te pay senetleri işlem gören 11 konaklama şirketinin 2017, 2018 ve 2019 yıllarında ekonomik, çevresel ve sosyal faktörler bağlamında gerçekleştirdikleri sürdürülebilirlik faaliyetleri ve bu faaliyetlerin raporlanmasıyla ilgili elde edilen analiz bulguları yer almaktadır. Söz konusu şirketler sürdürülebilirlik raporları yayınlamadıkları için yıllık faaliyet raporlarında yer verdikleri sürdürülebilirlik faaliyetlerinin incelenmesi sonucu elde edilen analiz bulguları 2017,2018 ve 2019 yılları için ayrı başıklar halinde sunulmaktadır. 


\subsection{BIST Konaklama Şirketlerinin 2017 Yılına Ait Bulguları}

BIST konaklama şirketlerinin 2017 yılı faaliyet raporlarında sundukları ekonomik unsurlar ile ilgili bilgiler Tablo 2' de yer almaktadır.

Tablo 2: BIST Konaklama Şirketlerinin 2017 Yılı Faaliyet Raporlarında Ekonomik Unsurlara Yer Verme Düzeyleri

\begin{tabular}{|l|c|c|c|c|c|c|}
\hline & \multicolumn{3}{|c|}{ Ekonomik Unsurlar } & \multicolumn{2}{c|}{ Toplam } \\
\hline Şirketler & A & B & C & D & $\sum$ & $\%$ \\
\hline 1.Altın Yunus Çeşme & $\checkmark$ & $\checkmark$ & $\checkmark$ & $\checkmark$ & 4 & 100 \\
\hline 2.Avrasya Turizm & $\checkmark$ & $\varnothing$ & $\checkmark$ & $\varnothing$ & 2 & 50 \\
\hline 3.Kuştur Kuşadası Turizm & $\checkmark$ & $\varnothing$ & $\varnothing$ & $\varnothing$ & 1 & 25 \\
\hline 4.Marmaris Altın Yunus & $\checkmark$ & $\varnothing$ & $\checkmark$ & $\varnothing$ & 2 & 50 \\
\hline 5.Mart1 Otel & $\checkmark$ & $\checkmark$ & $\checkmark$ & $\varnothing$ & 3 & 75 \\
\hline 6.Merit Turizm & $\checkmark$ & $\checkmark$ & $\checkmark$ & $\varnothing$ & 3 & 75 \\
\hline 7.Metemtur Turizm & $\checkmark$ & $\varnothing$ & $\varnothing$ & $\varnothing$ & 1 & 25 \\
\hline 8.Petrokent Turizm & $\checkmark$ & $\varnothing$ & $\checkmark$ & $\varnothing$ & 2 & 50 \\
\hline 9.Tek-Art Turizm & $\checkmark$ & $\varnothing$ & $\checkmark$ & $\varnothing$ & 2 & 50 \\
\hline 10.Ulaşlar Turizm & $\checkmark$ & $\varnothing$ & $\varnothing$ & $\varnothing$ & 1 & 25 \\
\hline 11.Utopya Turizm & $\checkmark$ & $\varnothing$ & $\checkmark$ & $\varnothing$ & 2 & 50 \\
\hline
\end{tabular}

Tablo içerisinde, A: Ekonomik performansı, B: Piyasa varlığını, C: Dolaylı ekonomik etkileri ve D: Satın alma uygulamalarını ifade etmektedir.

Tablo 2 incelendiğinde ekonomik unsurların tamamını sağlayan Altın Yunus Çeşme Turistik Tesisler A.Ş.'nin en yüksek performansa sahip olduğu görülmektedir. Analiz kapsamında yer alan üç şirket ise raporlarında ekonomik bağlamda sadece bir unsura yer vermişlerdir. Şirketlerin tamamının yer verdiği ekonomik unsur ekonomik performans verileri olurken; sadece Altın Yunus Çeşme Turistik Tesisler A.Ş.'nin yer vermiş olduğu unsur ise satın alma uygulamaları olmuştur. Ayrıca dolaylı ekonomik etkenler unsuruna da şirketlerin raporlarında öncelik tanıdıkları görülmektedir.

BIST konaklama şirketlerinin 2017 yılı faaliyet raporlarında sundukları çevresel unsurlar ile ilgili bilgiler Tablo 3' de yer almaktadır. Tablo 3 incelendiğinde 2017 yılında çevresel bağlamda en yüksek performansı gösteren şirketin, \%75 oran ve on iki unsurdan dokuzuna yer veren, Altın Yunus Çeşme Turistik Tesisler A.Ş. olduğu görülmektedir. Buna karşın iki konaklama şirketinin raporlarında çevresel hiçbir ifadeye yer vermediği görülmektedir. Şirketlerin 2017 yılında çevre ile ilgili raporlarında, çevresel unsurlar içerisinde en çok yer verilen unsurun çevresel duyarlılıkları ile ilgili faaliyetlerinin detay verilmeden genel bir yargıyla ifade edilmesini içeren "Genel" unsuru olurken; hiçbir şirketin yer vermediği unsur "tedarikçinin çevresel bakımdan değerlendirilmesi" olmuştur. Bu bağlamda 2017 yılında GRI standartlarına göre BIST konaklama şirketlerinin çevresel performansının oldukça düşük olduğu söylenebilir. 
Tablo 3: BIST Konaklama Şirketlerinin 2017 Yılı Faaliyet Raporlarında Çevresel Unsurlara Yer Verme Düzeyleri

\begin{tabular}{|l|c|c|c|c|c|c|c|c|c|c|c|c|c|c|}
\hline & \multicolumn{10}{|c|}{ Cevresel Unsurlar } & \multicolumn{10}{|c|}{ Toplam } \\
\hline & $\mathbf{E}$ & $\mathbf{F}$ & $\mathbf{G}$ & $\mathbf{H}$ & $\mathbf{I}$ & $\mathbf{I}$ & $\mathbf{J}$ & $\mathbf{K}$ & $\mathbf{L}$ & $\mathbf{M}$ & $\mathbf{N}$ & $\mathbf{O}$ & $\sum$ & \% \\
\hline 1.Altın Yunus Çeşme & $\checkmark$ & $\checkmark$ & $\checkmark$ & $\checkmark$ & $\checkmark$ & $\checkmark$ & $\checkmark$ & $\varnothing$ & $\checkmark$ & $\checkmark$ & $\varnothing$ & $\varnothing$ & 9 & 75 \\
\hline 2.Avrasya Turizm & $\varnothing$ & $\varnothing$ & $\varnothing$ & $\varnothing$ & $\varnothing$ & $\varnothing$ & $\varnothing$ & $\checkmark$ & $\varnothing$ & $\checkmark$ & $\varnothing$ & $\varnothing$ & 2 & 17 \\
\hline 3.Kuştur Kuşadası Turizm & $\checkmark$ & $\varnothing$ & $\varnothing$ & $\varnothing$ & $\varnothing$ & $\varnothing$ & $\varnothing$ & $\checkmark$ & $\varnothing$ & $\checkmark$ & $\varnothing$ & $\varnothing$ & 3 & 25 \\
\hline 4.Marmaris Altın Yunus & $\varnothing$ & $\varnothing$ & $\varnothing$ & $\varnothing$ & $\varnothing$ & $\varnothing$ & $\varnothing$ & $\checkmark$ & $\varnothing$ & $\checkmark$ & $\varnothing$ & $\varnothing$ & 2 & 17 \\
\hline 5.Mart1 Otel & $\varnothing$ & $\varnothing$ & $\varnothing$ & $\varnothing$ & $\varnothing$ & $\varnothing$ & $\varnothing$ & $\checkmark$ & $\varnothing$ & $\checkmark$ & $\varnothing$ & $\varnothing$ & 2 & 17 \\
\hline 6.Merit Turizm & $\varnothing$ & $\varnothing$ & $\varnothing$ & $\varnothing$ & $\varnothing$ & $\varnothing$ & $\varnothing$ & $\checkmark$ & $\varnothing$ & $\checkmark$ & $\varnothing$ & $\checkmark$ & 3 & 25 \\
\hline 7.Metemtur Turizm & $\varnothing$ & $\varnothing$ & $\varnothing$ & $\varnothing$ & $\varnothing$ & $\varnothing$ & $\varnothing$ & $\varnothing$ & $\varnothing$ & $\varnothing$ & $\varnothing$ & $\varnothing$ & 0 & 0 \\
\hline 8.Petrokent Turizm & $\varnothing$ & $\varnothing$ & $\varnothing$ & $\varnothing$ & $\varnothing$ & $\varnothing$ & $\varnothing$ & $\varnothing$ & $\varnothing$ & $\checkmark$ & $\varnothing$ & $\varnothing$ & 1 & 8 \\
\hline 9.Tek-Art Turizm & $\varnothing$ & $\varnothing$ & $\varnothing$ & $\varnothing$ & $\varnothing$ & $\varnothing$ & $\varnothing$ & $\checkmark$ & $\varnothing$ & $\checkmark$ & $\varnothing$ & $\varnothing$ & 2 & 17 \\
\hline 10.Ulaşlar Turizm & $\varnothing$ & $\varnothing$ & $\varnothing$ & $\varnothing$ & $\varnothing$ & $\varnothing$ & $\varnothing$ & $\varnothing$ & $\varnothing$ & $\varnothing$ & $\varnothing$ & $\varnothing$ & 0 & 0 \\
\hline 11.Utopya Turizm & $\varnothing$ & $\varnothing$ & $\varnothing$ & $\varnothing$ & $\varnothing$ & $\varnothing$ & $\varnothing$ & $\checkmark$ & $\varnothing$ & $\checkmark$ & $\varnothing$ & $\varnothing$ & 2 & 17 \\
\hline
\end{tabular}

Tablodaki kodlamalar, E: Malzemeler, F: Enerji, G: Su, H: Biyolojik Çeşitlilik, I: Emisyonlar, İ: Atık sular ve atıklar, J: Ürün ve hizmetler, K: Uyum, L: Nakliye, M: Genel, N: Tedarikçinin çevresel bakımdan değerlendirilmesi ve O: Çevresel şikâyet mekanizması şeklindedir.

Şirketlerin sürdürülebilirlik bağlamında sosyal unsurlara raporlarında yer verme düzeyleri Tablo 4'de gösterilmiştir. Tablo 4 incelendiğinde otuz adet sosyal unsurdan on sekizini karşılayan Altın Yunus Çeşme Turistik Tesisler A.Ş.'nin ilk sırada, yer aldığı görülmektedir. Şirketler, 2017 yılında sosyal faktörler bağlamında en fazla "istihdam ve işgücü/yönetim" unsurlarına yer verirken; "Tedarikçilerin iş gücü, insan hakları ve toplum üzerindeki etkileri bakımından değerlendirilmesi, rekabete aykırı davranış, toplumsal şikayet mekanizması ve müşteri sağlık ve güvenliği" unsurlarına ise yer vermemişlerdir. 
Tablo 4: BIST Konaklama Şirketlerinin 2017 Yılı Faaliyet Raporlarında Sosyal Unsurlara Yer Verme Düzeyleri

\begin{tabular}{|c|c|c|c|c|c|c|c|c|c|c|c|c|c|c|c|c|c|c|c|c|c|c|c|c|c|c|c|c|c|c|c|c|}
\hline & \multicolumn{30}{|c|}{ Sosyal Unsurlar } & \multirow{2}{*}{\multicolumn{2}{|c|}{ Toplam }} \\
\hline & \multicolumn{8}{|c|}{$\begin{array}{c}\text { İş Gücü Uygulamaları ve } \\
\text { İnsana Yaraşır İş }\end{array}$} & \multicolumn{10}{|c|}{ İnsan Hakları } & \multicolumn{7}{|c|}{ Toplum } & \multicolumn{5}{|c|}{ Ürün Sorumluluğu } & & \\
\hline Şirketler & $\mathbf{A}$ & B & $\mathrm{C}$ & $\mathbf{D}$ & $\mathbf{E}$ & $\mathbf{F}$ & $\mathbf{G}$ & $\mathbf{H}$ & I & I & $\mathrm{J}$ & $\mathbf{K}$ & $\mathbf{L}$ & $\mathbf{M}$ & $\mathbf{N}$ & & Ö & $\mathbf{P}$ & $\mathbf{R}$ & $\mathbf{S}$ & Ş & $\mathbf{T}$ & $\mathbf{U}$ & $\ddot{\mathrm{U}}$ & $\mathbf{V}$ & $\mathbf{Y}$ & $\mathbf{Z}$ & $A_{1}$ & $\mathbf{B}_{1}$ & $\mathrm{C}_{1}$ & $\sum$ & $\%$ \\
\hline 1.Altın Yunus Çeşme & $\checkmark$ & $\checkmark$ & $\checkmark$ & $\checkmark$ & 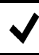 & $\checkmark$ & $\varnothing$ & $\checkmark$ & $\checkmark$ & $\checkmark$ & 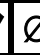 & $\varnothing$ & $\varnothing$ & $\checkmark$ & $\varnothing$ & $\checkmark$ & $\varnothing$ & $\checkmark$ & $\varnothing$ & $\varnothing$ & $\checkmark$ & $\varnothing$ & $\checkmark$ & $\varnothing$ & $\varnothing$ & $\varnothing$ & $\checkmark$ & $\checkmark$ & $\checkmark$ & $\checkmark$ & 18 & 60 \\
\hline 2.Avrasya Turizm & $\checkmark$ & $\checkmark$ & $\checkmark$ & $\checkmark$ & $\checkmark$ & $\varnothing$ & $\varnothing$ & $\varnothing$ & $\varnothing$ & $v$ & $\ell$ & $\varnothing$ & $\varnothing$ & $\checkmark$ & $\varnothing$ & $\checkmark$ & $\varnothing$ & $\varnothing$ & $\varnothing$ & $\varnothing$ & $\varnothing$ & $\varnothing$ & $\checkmark$ & $\varnothing$ & $\varnothing$ & $\varnothing$ & $\varnothing$ & $\varnothing$ & $\varnothing$ & $\varnothing$ & 9 & 30 \\
\hline 3.Kuştur Kuşadas1 & $\checkmark$ & $\checkmark$ & $\varnothing$ & $\checkmark$ & $\varnothing$ & $\varnothing$ & $\varnothing$ & $\varnothing$ & $\checkmark$ & $\checkmark$ & $\ell$ & $\varnothing$ & $\varnothing$ & $\varnothing$ & $\varnothing$ & $\checkmark$ & $\varnothing$ & $\varnothing$ & $\varnothing$ & $\varnothing$ & $\checkmark$ & $\varnothing$ & $\checkmark$ & $\varnothing$ & $\varnothing$ & $\varnothing$ & $\checkmark$ & $\varnothing$ & $\varnothing$ & $\checkmark$ & 10 & 33 \\
\hline 4.Marmaris Altın Yun. & $\checkmark$ & $\checkmark$ & $\checkmark$ & $\checkmark$ & $\varnothing$ & $\varnothing$ & $\varnothing$ & $\varnothing$ & $\varnothing$ & $\checkmark$ & $\ell$ & $\varnothing$ & $\varnothing$ & $\varnothing$ & $\varnothing$ & $\checkmark$ & $\varnothing$ & $\checkmark$ & $\varnothing$ & $\varnothing$ & $\varnothing$ & $\varnothing$ & $\varnothing$ & $\varnothing$ & $\varnothing$ & $\varnothing$ & $\varnothing$ & $\varnothing$ & $\varnothing$ & $\varnothing$ & 7 & 23 \\
\hline 5.Mart1 Otel & $\checkmark$ & $\checkmark$ & $\varnothing$ & $\checkmark$ & $\varnothing$ & $\checkmark$ & $\varnothing$ & $\varnothing$ & $\checkmark$ & $v$ & $v$ & $\checkmark$ & $\checkmark$ & $\varnothing$ & $\checkmark$ & $\checkmark$ & $\varnothing$ & $\varnothing$ & $\checkmark$ & $\checkmark$ & $\varnothing$ & $\varnothing$ & $\checkmark$ & $\varnothing$ & $\varnothing$ & $\varnothing$ & $\checkmark$ & $\varnothing$ & $\varnothing$ & $\checkmark$ & 16 & 53 \\
\hline 6.Merit Turizm & $\checkmark$ & $\checkmark$ & $\varnothing$ & $\varnothing$ & $\checkmark$ & $\checkmark$ & $\varnothing$ & $\checkmark$ & $\checkmark$ & 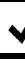 & $\underline{\ell}$ & $\varnothing$ & $\varnothing$ & $\checkmark$ & $\varnothing$ & $\checkmark$ & $\varnothing$ & $\checkmark$ & $\varnothing$ & $\varnothing$ & $\checkmark$ & $\varnothing$ & $\checkmark$ & $\varnothing$ & $\varnothing$ & $\varnothing$ & $\checkmark$ & $\varnothing$ & $\varnothing$ & $\checkmark$ & 14 & 47 \\
\hline 7.Metemtur Turizm & $\checkmark$ & $\checkmark$ & $\varnothing$ & $\varnothing$ & $\varnothing$ & $\varnothing$ & $\varnothing$ & $\varnothing$ & $\varnothing$ & $\ell$ & $\ell$ & $\varnothing$ & $\varnothing$ & $\varnothing$ & $\varnothing$ & $\varnothing$ & $\varnothing$ & $\varnothing$ & $\varnothing$ & $\varnothing$ & $\varnothing$ & $\varnothing$ & $\varnothing$ & $\varnothing$ & $\varnothing$ & $\varnothing$ & $\varnothing$ & $\varnothing$ & $\varnothing$ & $\varnothing$ & 2 & 7 \\
\hline 8.Petrokent Turizm & $\checkmark$ & $\checkmark$ & $\varnothing$ & $\checkmark$ & $\checkmark$ & $\varnothing$ & $\varnothing$ & $\checkmark$ & $\varnothing$ & $v$ & \& & $\varnothing$ & $\varnothing$ & $\varnothing$ & $\varnothing$ & $\checkmark$ & $\varnothing$ & $\checkmark$ & $\varnothing$ & $\varnothing$ & $\varnothing$ & $\varnothing$ & $\varnothing$ & $\varnothing$ & $\varnothing$ & $\varnothing$ & $\varnothing$ & $\varnothing$ & $\varnothing$ & $\varnothing$ & 8 & 27 \\
\hline 9.Tek-Art Turizm & $\checkmark$ & $\varnothing$ & $\checkmark$ & $\checkmark$ & $\checkmark$ & $\varnothing$ & $\varnothing$ & $\varnothing$ & $v$ & $v$ & $\underline{\ell}$ & $\varnothing$ & $\varnothing$ & $\varnothing$ & $\checkmark$ & $\checkmark$ & $\varnothing$ & $\checkmark$ & $\checkmark$ & $\varnothing$ & $\varnothing$ & $\varnothing$ & $\checkmark$ & $\varnothing$ & $\varnothing$ & $\varnothing$ & $\varnothing$ & $\varnothing$ & $\varnothing$ & $\varnothing$ & 11 & 37 \\
\hline 10.Ulaşlar Turizm & $\checkmark$ & $\checkmark$ & $\varnothing$ & $\varnothing$ & $\varnothing$ & $\varnothing$ & $\varnothing$ & $\varnothing$ & $\varnothing$ & $\ell$ & e & $\varnothing$ & $\varnothing$ & $\varnothing$ & $\varnothing$ & $\varnothing$ & $\varnothing$ & $\varnothing$ & $\varnothing$ & $\varnothing$ & $\varnothing$ & $\varnothing$ & $\varnothing$ & $\varnothing$ & $\varnothing$ & $\varnothing$ & $\varnothing$ & $\varnothing$ & $\varnothing$ & $\varnothing$ & 2 & 7 \\
\hline 11.Utopya Turizm & $\varnothing$ & $\checkmark$ & $\varnothing$ & $\checkmark$ & $\varnothing$ & $\varnothing$ & $\varnothing$ & $\varnothing$ & $v$ & $\ell$ & $\ell$ & $\varnothing$ & $\varnothing$ & $\varnothing$ & $\varnothing$ & $\checkmark$ & $\varnothing$ & $\varnothing$ & $\varnothing$ & $\varnothing$ & $\checkmark$ & $\varnothing$ & $\varnothing$ & $\varnothing$ & $\varnothing$ & $\varnothing$ & $\checkmark$ & $\varnothing$ & $\varnothing$ & $\varnothing$ & 6 & 20 \\
\hline
\end{tabular}

Tablodaki kodlamalar, A: İstihdam, B: İsgücü /Yönetim İlișkileri, C: İs Sağlığı ve güvenliği, D: Eğitim ve öğretim, E: Ceșitlilik ve fırsat eșitliği, F: Kadın erkek için eșit ücret, G: Tedarikçinin işgücü uygulamaları bakımından değerlendirilmesi ve H: İş gücü uygulamaları şikayet mekanizması, I: Yatırım, İ: Ayrımcilığın önlenmesi, J: Örgütlenme ve toplu sözleşme hakkı, K: Çocuk iş̧̧iler, L: Zorla veya cebren çalıştırma, M: Güvenlik uygulamaları, N: Yerli halkların hakları, O:Değerlendirme, Ö:Tedarikçilerin insan hakları bakımından değerlendirilmesi, P: İnsan hakları şikayet mekanizması, R:Yerel Toplumlar, S:Yolsuzlukla mücadele, Ş:Kamu Politikası, T:Rekabete aykırı davranış, U:Uyum, Ü:Tedarikçilerin Toplum üzerindeki etkiler bakımından değerlendirilmesi, V:Toplum üzerindeki etkilere ilişkin şikayet mekanizması, Y:Müşteri sağlığı ve güvenliği, Z:Ürün ve hizmet etiketlemesi, A1: Pazarlama iletişimi, B1: Müşteri gizliliği ve C1: Uyum’dan oluşmaktadır. 


\subsection{BIST Konaklama Şirketlerinin 2018 Yılına Ait Bulguları}

BIST' te işlem gören konaklama şirketlerinin 2018 yılı faaliyet raporları ekonomik, çevresel ve sosyal kategorileri altında incelendiğinde elde edilen sonuçlar tablolar halinde aşağıda yer almaktadır. Bu bağlamda ilk olarak ekonomik unsurlar çerçevesinde değerlendirilen şirketlerin 2018 yılına ait analiz bulguları Tablo 5'de belirtilmiştir.

Tablo 5: BIST Konaklama Şirketlerinin 2018 Yılı Faaliyet Raporlarında EkonomikUnsurlara Yer Verme Düzeyleri

\begin{tabular}{|l|c|c|c|c|c|c|}
\hline & \multicolumn{3}{|c|}{ Ekonomik Unsurlar } & \multicolumn{2}{c|}{ Toplam } \\
\hline Şirketler & A & B & C & D & $\sum$ & $\%$ \\
\hline 1.Altın Yunus Çeșme & $\checkmark$ & $\checkmark$ & $\checkmark$ & $\checkmark$ & 4 & 100 \\
\hline 2.Avrasya Turizm & $\checkmark$ & $\varnothing$ & $\checkmark$ & $\varnothing$ & 2 & 50 \\
\hline 3.Kuştur Kuşadası Turizm & $\checkmark$ & $\varnothing$ & $\varnothing$ & $\varnothing$ & 1 & 25 \\
\hline 4.Marmaris Altın Yunus & $\checkmark$ & $\varnothing$ & $\checkmark$ & $\varnothing$ & 2 & 50 \\
\hline 5.Martı Otel & $\checkmark$ & $\checkmark$ & $\checkmark$ & $\varnothing$ & 3 & 75 \\
\hline 6.Merit Turizm & $\checkmark$ & $\varnothing$ & $\checkmark$ & $\varnothing$ & 2 & 50 \\
\hline 7.Metemtur Turizm & $\checkmark$ & $\varnothing$ & $\varnothing$ & $\varnothing$ & 1 & 25 \\
\hline 8.Petrokent Turizm & $\checkmark$ & $\varnothing$ & $\checkmark$ & $\varnothing$ & 2 & 50 \\
\hline 9.Tek-Art Turizm & $\checkmark$ & $\varnothing$ & $\checkmark$ & $\varnothing$ & 2 & 50 \\
\hline 10.Ulaşlar Turizm & $\checkmark$ & $\varnothing$ & $\varnothing$ & $\varnothing$ & 1 & 25 \\
\hline 11.Utopya Turizm & $\checkmark$ & $\varnothing$ & $\checkmark$ & $\varnothing$ & 2 & 50 \\
\hline
\end{tabular}

Tablodaki kodlamalar; A: Ekonomik performans, B: Piyasa varlığı, C: Dolaylı ekonomik etkiler ve D: Satın alma uygulamaları şeklindedir.

Tablo 5 incelendiğinde 2017 yılında olduğu gibi şirketlerin tamamının 2018 yılı faaliyet raporlarında ekonomik unsurlar içerisinde "ekonomik performans" unsuruna yer verdiği, en az yer verilen unsurun ise "satın alma uygulamaları" olduğu görülmektedir. Ayrıca "piyasa varlığı" unsurunun da yine şirketler arasında sıklıkla yer verilmeyen unsur olduğu analiz sonucu elde edilen bulgular arasındadır. BIST konaklama şirketlerinden Altın Yunus Çeşme Turistik Tesisler A.Ş., 2017 yılında olduğu gibi tüm ekonomik unsurlara 2018 yılı faaliyet raporunda da yer vererek ilk sırada yer almıştır.

BIST konaklama şirketlerinin 2018 yılında çevresel bağlamda göstermiş oldukları performanslar Tablo 6'da belirtilmiştir. Tablo 6 incelendiğinde şirketlerin 2017 yılında olduğu gibi en fazla "genel" unsuruna raporlarında yer verip, çevre ile ilgili genel bir yargıda bulundukları görülmektedir. Buna karşın 2017 yılından farklı olarak "biyolojik çeşitlilik ve nakliye unsurları" ile ilgili ise hiçbir şirket açıklama yapmamış ve raporlarında bu bilgileri kapsayan ifadelere yer vermemişlerdir. Çevresel faktörler bağlamında on iki unsurdan dokuzunu sağlayan Altın Yunus Çeşme Turistik Tesisler A.Ş., 2018 yılında da ilk sırada yer almıştır. Çevre ile ilgili analiz yapıldığında 2018 yılında, 2017 yılına göre daha fazla şirketin hiçbir çevresel unsura raporlarında yer vermediği saptanmıştır. Bu bağlamda çevresel performans açısından analiz kapsamındaki konaklama şirketlerinin performanslarının 2018 yılında düştüğünü söylemek mümkündür. 
Tablo 6: BIST Konaklama Şirketlerinin 2018 Yılı Faaliyet Raporlarında Çevresel Unsurlara Yer Verme Düzeyleri

\begin{tabular}{|l|c|c|c|c|c|c|c|c|c|c|c|c|c|c|}
\hline & \multicolumn{10}{|c|}{ Cevresel Unsurlar } & \multicolumn{1}{|c|}{ Toplam } \\
\hline Şirketler & $\mathbf{E}$ & $\mathbf{F}$ & $\mathbf{G}$ & $\mathbf{H}$ & $\mathbf{I}$ & $\mathbf{I}$ & $\mathbf{J}$ & $\mathbf{K}$ & $\mathbf{L}$ & $\mathbf{M}$ & $\mathbf{N}$ & $\mathbf{O}$ & $\sum$ & $\%$ \\
\hline 1.Altın Yunus Çeşme & $\checkmark$ & $\checkmark$ & $\checkmark$ & $\varnothing$ & $\checkmark$ & $\checkmark$ & $\boldsymbol{V}$ & $\checkmark$ & $\varnothing$ & $\checkmark$ & $\checkmark$ & $\varnothing$ & 9 & 75 \\
\hline 2.Avrasya Turizm & $\varnothing$ & $\varnothing$ & $\varnothing$ & $\varnothing$ & $\varnothing$ & $\varnothing$ & $\varnothing$ & $\varnothing$ & $\varnothing$ & $\varnothing$ & $\varnothing$ & $\varnothing$ & 0 & 0 \\
\hline 3.Kuştur Kuşadası Tur. & $\checkmark$ & $\varnothing$ & $\varnothing$ & $\varnothing$ & $\varnothing$ & $\varnothing$ & $\varnothing$ & $\checkmark$ & $\varnothing$ & $\checkmark$ & $\varnothing$ & $\varnothing$ & 3 & 25 \\
\hline 4.Marmaris Altın Yun. & $\varnothing$ & $\varnothing$ & $\varnothing$ & $\varnothing$ & $\varnothing$ & $\varnothing$ & $\varnothing$ & $\checkmark$ & $\varnothing$ & $\checkmark$ & $\varnothing$ & $\varnothing$ & 2 & 17 \\
\hline 5.Martı Otel & $\varnothing$ & $\varnothing$ & $\varnothing$ & $\varnothing$ & $\varnothing$ & $\varnothing$ & $\varnothing$ & $\checkmark$ & $\varnothing$ & $\checkmark$ & $\varnothing$ & $\varnothing$ & 2 & 17 \\
\hline 6.Merit Turizm & $\varnothing$ & $\varnothing$ & $\varnothing$ & $\varnothing$ & $\varnothing$ & $\varnothing$ & $\varnothing$ & $\varnothing$ & $\varnothing$ & $\varnothing$ & $\varnothing$ & $\varnothing$ & 0 & 0 \\
\hline 7.Metemtur Turizm & $\varnothing$ & $\varnothing$ & $\varnothing$ & $\varnothing$ & $\varnothing$ & $\varnothing$ & $\varnothing$ & $\varnothing$ & $\varnothing$ & $\varnothing$ & $\varnothing$ & $\varnothing$ & 0 & 0 \\
\hline 8.Petrokent Turizm & $\varnothing$ & $\varnothing$ & $\varnothing$ & $\varnothing$ & $\varnothing$ & $\varnothing$ & $\varnothing$ & $\varnothing$ & $\varnothing$ & $\checkmark$ & $\varnothing$ & $\varnothing$ & 1 & 8 \\
\hline 9.Tek-Art Turizm & $\varnothing$ & $\varnothing$ & $\varnothing$ & $\varnothing$ & $\varnothing$ & $\varnothing$ & $\varnothing$ & $\checkmark$ & $\varnothing$ & $\checkmark$ & $\varnothing$ & $\checkmark$ & 3 & 25 \\
\hline 10.Ulaşlar Turizm & $\varnothing$ & $\varnothing$ & $\varnothing$ & $\varnothing$ & $\varnothing$ & $\varnothing$ & $\varnothing$ & $\varnothing$ & $\varnothing$ & $\varnothing$ & $\varnothing$ & $\varnothing$ & 0 & 0 \\
\hline 11.Utopya Turizm & $\varnothing$ & $\varnothing$ & $\varnothing$ & $\varnothing$ & $\varnothing$ & $\varnothing$ & $\varnothing$ & $\checkmark$ & $\varnothing$ & $\checkmark$ & $\varnothing$ & $\varnothing$ & 2 & 17 \\
\hline
\end{tabular}

Tablodaki kodlamalar; E: Malzemeler, F: Enerji, G: Su, H: Biyolojik Çeşitlilik, I: Emisyonlar, İ: Atık sular ve atıklar, J: Ürün ve hizmetler, K: Uyum, L: Nakliye, M: Genel, N: Tedarikçinin çevresel bakımdan değerlendirilmesi ve O: Çevresel şikâyet mekanizması şeklindedir.

2018 yılı faaliyet raporları kapsamında sosyal faktörler çerçevesinde incelenen şirketlerin göstermiş oldukları performans verileri ise Tablo 7 'de yer almaktadır. Tablo 7 'de sosyal kategori altında toplam otuz unsur bulunmaktadır. Tablo 7 incelendiğinde 2017 yılında olduğu gibi Altın Yunus Çeşme Turistik Tesisler A.Ş.'nin en yüksek oranda bu unsurlara yer vererek ilk sırada yer aldığı görülmektedir. Şirketler 2018 yılında, 2017 yılında olduğu gibi sosyal bağlamda en fazla "istihdam ve işgücü/yönetim" unsurlarına raporlarında yer verirken; "tedarikçinin işgücü uygulamaları, insan hakları ve toplum üzerindeki etkileri bakımından değerlendirilmesi, işgücü uygulamaları şikayet mekanizması, rekabete aykırı davranış ve müşteri sağlık ve güvenliği" unsurlarına hiç yer verilmedikleri saptanmıştır. 
Tablo 7: BIST Konaklama Şirketlerinin 2018 Yılı Faaliyet Raporlarında Sosyal Unsurlara Yer Verme Düzeyleri

\begin{tabular}{|c|c|c|c|c|c|c|c|c|c|c|c|c|c|c|c|c|c|c|c|c|c|c|c|c|c|c|c|c|}
\hline & \multicolumn{26}{|c|}{ Sosyal Unsurlar } & \multirow{2}{*}{\multicolumn{2}{|c|}{ Toplam }} \\
\hline & \multicolumn{7}{|c|}{$\begin{array}{c}\text { İş Gücü Uygulamaları ve } \\
\text { İnsana Yaraşır İș }\end{array}$} & \multicolumn{9}{|c|}{ 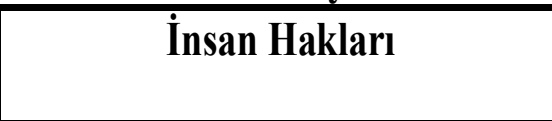 } & \multicolumn{5}{|c|}{ Toplum } & \multicolumn{5}{|c|}{ Ürün Sorumluluğu } & & \\
\hline Sirketler & \begin{tabular}{|l|l}
$A$ \\
\end{tabular} & B & \begin{tabular}{l|l}
$\mathrm{C}$ & $\mathrm{I}$ \\
\end{tabular} & \begin{tabular}{|l|l} 
& $E$
\end{tabular} & $F$ & & $\bar{H}$ & & i & & & $\mathrm{M}$ & $\mathbf{N}$ & & Ö & $\mathbf{P}$ & \begin{tabular}{l|l}
$\mathbf{R}$ & $\mathrm{s}$ \\
\end{tabular} & & $\mathrm{T}$ & \begin{tabular}{|l|l|}
$\mathbf{U}$ & $\ddot{\mathbf{U}}$ \\
\end{tabular} & $\mathrm{V}$ & $\mathbf{Y}$ & $\mathrm{Z}$ & $\mathbf{A}_{1}$ & $\mathbf{B}_{1}$ & $C_{1}$ & & $\%$ \\
\hline 1.Altın Yunus & 1 & $\checkmark$ & $\sqrt{v}$ & $\sqrt{v}$ & $\checkmark$ & $\varnothing$ & $\varnothing$ & & $\sqrt{1}$ & & 96 & a & $\varnothing$ & $\checkmark$ & $\varnothing$ & $\checkmark$ & $\varnothing \mid$ & $\gamma \mid v$ & $\varnothing$ & \begin{tabular}{|l|l|}
$\checkmark$ & $\varnothing$ \\
\end{tabular} & $\varnothing$ & $\varnothing$ & $\checkmark$ & $\checkmark$ & $\checkmark$ & $\checkmark$ & 17 & 57 \\
\hline 2.Avrasya Turizm & $\checkmark$ & $\checkmark$ & $\varnothing \ell$ & $\bar{\gamma} \varnothing$ & $\varnothing$ & $\ell$ & $\varnothing$ & & $\varnothing$ & & 18 & $\varnothing$ & $\varnothing$ & $\varnothing$ & $\varnothing$ & $\varnothing$ & 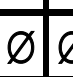 & & $\varnothing$ & \begin{tabular}{|l|l|}
$\varnothing$ & $\varnothing$ \\
\end{tabular} & $\varnothing$ & $\varnothing$ & $\varnothing$ & $\varnothing$ & $\varnothing$ & $\varnothing$ & 3 & 10 \\
\hline 3.Kuştur Kuşadası Tur. & $|\nabla|$ & $\checkmark$ & $\varnothing$ & 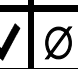 & $\varnothing$ & $\varnothing$ & $\varnothing$ & & $\sqrt{1}$ & & $x \mid 6$ & $x$ & $\varnothing$ & $\checkmark$ & $\varnothing$ & $\varnothing$ & $\varnothing \mid \ell$ & $\gamma \mid v$ & $\varnothing$ & \begin{tabular}{|l|l|}
$\checkmark$ & $\varnothing$ \\
\end{tabular} & $\varnothing$ & $\varnothing$ & $\checkmark$ & $\varnothing$ & $\varnothing$ & $\checkmark$ & 10 & 33 \\
\hline 4.Marmaris Altın Yun. & $\checkmark$ & $\sqrt{v}$ & $\sqrt{1}$ & $\sqrt{\varnothing}$ & $\varnothing$ & $\varnothing$ & $\varnothing$ & & $\sqrt{1}$ & & $x \sqrt{6}$ & $\bar{\varnothing}$ & $\varnothing$ & $\checkmark$ & $\varnothing$ & $\checkmark$ & $\varnothing \varnothing$ & $\bar{\varnothing} \varnothing$ & $\varnothing$ & \begin{tabular}{|l|l|}
$\varnothing$ & $\varnothing$ \\
\end{tabular} & $\varnothing$ & $\varnothing$ & $\varnothing$ & $\varnothing$ & $\varnothing$ & $\varnothing$ & 7 & 23 \\
\hline 5.Mart & 5 & $\checkmark$ & $\varnothing$ & 10 & $\varnothing$ & $\varnothing$ & $\varnothing$ & & $\sqrt{1}$ & & & $1 e$ & $\checkmark$ & $\checkmark$ & $\varnothing$ & $\varnothing$ & $\sqrt{2}$ & $\sqrt{\varnothing}$ & $\varnothing$ & \begin{tabular}{|l|l|}
$\checkmark$ & $\varnothing$ \\
\end{tabular} & $\varnothing$ & $\varnothing$ & $\checkmark$ & $\varnothing$ & $\varnothing$ & $\checkmark$ & 15 & 50 \\
\hline 6.Merit Turizm & $\varnothing$ & $\varnothing$ & $\overline{\varnothing \ell}$ & $\bar{\varnothing} \varnothing$ & $\varnothing$ & $\varnothing$ & $\varnothing$ & & $\varnothing$ & & & $\sqrt{e}$ & $\varnothing$ & $\varnothing$ & $\varnothing$ & $\varnothing$ & $\varnothing e$ & $\bar{\varnothing}$ & $\varnothing$ & \begin{tabular}{|l|l|}
$\varnothing$ & $\varnothing$ \\
\end{tabular} & $\varnothing$ & $\varnothing$ & $\checkmark$ & $\varnothing$ & $\varnothing$ & $\varnothing$ & 1 & 3 \\
\hline 7.Metemtur Turizm & $\sqrt{1}$ & $\sqrt{1}$ & $\varnothing] 6$ & $\bar{\varnothing} \varnothing$ & $\varnothing$ & $\varnothing$ & $\varnothing$ & & $\varnothing$ & & $x \sqrt{6}$ & $\bar{\varnothing}$ & $\varnothing$ & $\varnothing$ & $\varnothing$ & $\varnothing$ & $\varnothing e$ & $\bar{\phi} \varnothing$ & $\varnothing$ & \begin{tabular}{l|l}
$\varnothing$ & $\varnothing$ \\
\end{tabular} & $\varnothing$ & $\varnothing$ & $\varnothing$ & $\varnothing$ & $\varnothing$ & $\varnothing$ & 2 & 7 \\
\hline 8.Petrokent Turizm & $v$ & $\checkmark$ & $\varnothing$ & $\sqrt{v}$ & $\varnothing$ & $\varnothing$ & $\varnothing$ & & $\sqrt{1}$ & & & $x$ & $\varnothing$ & $\checkmark$ & $\varnothing$ & $\checkmark$ & $\varnothing \ell$ & 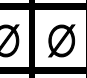 & $\varnothing$ & \begin{tabular}{|l|l|}
$\varnothing$ & $\varnothing$ \\
\end{tabular} & $\varnothing$ & $\varnothing$ & $\varnothing$ & $\varnothing$ & $\varnothing$ & $\varnothing$ & 7 & 23 \\
\hline 9.Tek-Art Turizm & $\sqrt{2}$ & & V. & $\sqrt{ }$ & $\varnothing$ & $\bar{\varnothing}$ & $\varnothing$ & & $\sqrt{ }$ & & & $x$ & $\checkmark$ & $\checkmark$ & $\varnothing$ & $\checkmark$ & $\sqrt{l e}$ & $\bar{\varnothing}$ & $\varnothing$ & \begin{tabular}{|l|l|}
$\checkmark$ & $\varnothing$ \\
\end{tabular} & $\varnothing$ & $\varnothing$ & $\varnothing$ & $\varnothing$ & $\varnothing$ & $\varnothing$ & 11 & 37 \\
\hline 10.Ulaşlar Turizm & $\sqrt{\mid}$ & $\sqrt{1}$ & $\bar{\varnothing} 6$ & $\bar{\phi} \varnothing$ & $\varnothing$ & 6 & $\varnothing$ & & $\varnothing$ & & & te & $\varnothing$ & $\varnothing$ & $\varnothing$ & $\varnothing$ & $\varnothing \mid e$ & $\bar{\phi} \varnothing$ & $\varnothing$ & \begin{tabular}{|l|l|}
$\varnothing$ & $\varnothing$ \\
\end{tabular} & $\varnothing$ & $\varnothing$ & $\checkmark$ & $\varnothing$ & $\varnothing$ & $\varnothing$ & 3 & 10 \\
\hline 11.Utopya Turizm & $\varnothing$ & & & $\sqrt{\varnothing}$ & $\varnothing$ & & 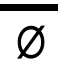 & & $\varnothing$ & & & & $\varnothing$ & & & $\varnothing$ & & & $\varnothing$ & \begin{tabular}{|l|l|}
$\varnothing$ & $\varnothing$ \\
\end{tabular} & $\varnothing$ & $\varnothing 1$ & $\checkmark$ & $\varnothing$ & $\varnothing$ & $\varnothing$ & 6 & 20 \\
\hline
\end{tabular}

Tablodaki kodlamalar; A: İstihdam, B: İşgücü /Yönetim İlişkileri, C: İş Sağlığı ve güvenliği, D: Eğitim ve öğretim, E: Çeşitlilik ve firsat eşitliği, F: Kadın erkek için eşit ücret G: Tedarikçinin işgücü uygulamaları bakımından değerlendirilmesi ve H: İ̧̧ gücü uygulamaları şikayet mekanizması, I: Yatırım, İ: Ayrımcıllğın önlenmesi, J: Örgütlenme ve toplu sözleşme hakkı, K: Çocuk iş̧̧iler, L: Zorla veya cebren çalıştırma, M: Güvenlik uygulamaları, N: Yerli halkların hakları, O:Değerlendirme, Ö:Tedarikçilerin insan hakları bakımından değerlendirilmesi, P: İnsan haklanı şikayet mekanizması, R:Yerel Toplumlar, S:Yolsuzlukla mücadele, Ş:Kamu Politikası, T:Rekabete aykırı davranış, U:Uyum, Ü:Tedarikçilerin Toplum üzerindeki etkiler bakımından değerlendirilmesi, V:Toplum üzerindeki etkilere ilişkin şikayet mekanizması, Y:Müşteri sağlığı ve güvenliği, Z:Ürün ve hizmet etiketlemesi, A1: Pazarlama iletişimi, B1: Müşteri gizliliği ve C1: Uyum şeklindedir. 


\subsection{BIST Konaklama Şirketlerinin 2019 Yılına Ait Bulguları}

BIST' te işlem gören konaklama şirketlerinin 2019 yılı faaliyet raporları ekonomik, çevresel ve sosyal kategorileri altında incelendiğinde elde edilen sonuçlar tablolar halinde aşağıda yer almaktadır. Tek-Art Turizm, 2019 yılı faaliyet raporunu henüz yayınlamadığından bu bölümde araştırma kapsamında yer almamaktadır. Bu bağlamda ilk olarak ekonomik unsurlar çerçevesinde değerlendirilen şirketlerin 2019 yılına ait analiz bulguları Tablo 8'de sunulmaktadır.

Tablo 8: BIST Konaklama Şirketlerinin 2019 Yılı Faaliyet Raporlarında Ekonomik Unsurlara Yer Verme Düzeyleri

\begin{tabular}{|l|c|c|c|c|c|c|}
\hline & \multicolumn{4}{|c|}{ Ekonomik } & \multicolumn{2}{c|}{ Toplam } \\
\hline Şirketler & A & B & C & D & $\sum$ & \% \\
\hline 1.Altın Yunus Çeşme & $\checkmark$ & $\checkmark$ & $\checkmark$ & $\checkmark$ & 4 & 100 \\
\hline 2.Avrasya Petrol & $\checkmark$ & $\checkmark$ & $\checkmark$ & $\emptyset$ & 3 & 75 \\
\hline 3.Kuştur Kuşadası Turizm & $\checkmark$ & $\emptyset$ & $\emptyset$ & $\emptyset$ & 1 & 25 \\
\hline 4.Marmaris Altın Yunus & $\checkmark$ & $\checkmark$ & $\checkmark$ & $\emptyset$ & 3 & 75 \\
\hline 5. Martı Otel & $\checkmark$ & $\checkmark$ & $\checkmark$ & $\emptyset$ & 3 & 75 \\
\hline 6.Merit Turizm & $\checkmark$ & $\checkmark$ & $\checkmark$ & $\emptyset$ & 3 & 75 \\
\hline 7.Metemtur Turizm & $\checkmark$ & $\emptyset$ & $\emptyset$ & $\emptyset$ & 1 & 25 \\
\hline 8.Petrokent Turizm & $\checkmark$ & $\emptyset$ & $\checkmark$ & $\emptyset$ & 2 & 50 \\
\hline 9.Tek-Art Turizm & & & & & & \\
\hline 10.Ulaşlar Turizm & $\checkmark$ & $\emptyset$ & $\emptyset$ & $\emptyset$ & 1 & 25 \\
\hline 11.Utopya Turizm & $\checkmark$ & $\checkmark$ & $\checkmark$ & $\emptyset$ & 3 & 75 \\
\hline
\end{tabular}

Tablo içerisinde, A: Ekonomik performansı, B: Piyasa varlığını, C: Dolaylı ekonomik etkileri ve D: Satın alma uygulamaların ifade etmektedir.

BIST konaklama şirketlerinin 2019 yılı faaliyet raporlarının ekonomik unsurları sağlama düzeyleri incelendiğinde "Ekonomik Performans" unsuruna tüm şirketlerin yer verdiği, raporlarda en az yer verilen unsurun ise sadece Altın Yunus Çeşme Turistik Tesisler A.Ş.'nin yer vermiş olduğu “Satın Alma Uygulamaları" olduğu görülmektedir. Ekonomik unsurların tamamına yer veren tek şirketin ise 2017 ve 2018 yıllarında olduğu gibi yineAltın Yunus Çeşme Turistik Tesisler A.Ş. olduğu görülmektedir.

Çevresel unsurlar bağlamında incelenen şirketlerin bu unsurları sağlama durumları Tablo 9'da belirtilmiştir. Bu bağlamda çevresel unsurlar içerisinde yine en fazla yer verilen unsurun "Genel" olduğu, şirketlerin çevresel duyarlılıkları ile ilgili detaylı bilgilerden ziyade genel bir yargıya yer verdikleri görülmektedir. 2019 yılında da "biyolojik çeşitlilik ve nakliye unsurları" ile ilgili hiçbir şirket açıklama yapmamış ve raporlarında bu bilgileri kapsayan ifadelere yer vermemişlerdir. 2017 ve 2018 yıllarında olduğu gibi 2019 yılında da çevresel unsurlara raporlarında yüksek oranda yer veren şirket Altın Yunus Çeşme Turistik Tesisler A.Ş. olmuştur. Avrasya Petrol ve Turistik Tesisler A.Ş., Kuştur Kuşadası Turizm Endüstrisi A.Ş., Metemtur Otelcilik ve Turizm İşletmeleri A.Ş. ve Ulaşlar Turizm Yatırım ve Dayanıklı Tüketim Malları A.Ş'nin ise çevresel unsurların hiçbirine 2019 yılı faaliyet raporunda yer vermediği görülmektedir. 
Tablo 9: BIST Konaklama Şirketlerinin 2019 Yılı Faaliyet Raporlarında Çevresel Unsurlara Yer Verme Düzeyleri

\begin{tabular}{|c|c|c|c|c|c|c|c|c|c|c|c|c|c|c|}
\hline & \multicolumn{14}{|c|}{ Çevresel } \\
\hline & $\bar{E}$ & $\bar{F}$ & $\bar{G}$ & $\mathbf{H}$ & $I$ & $\mathbf{i}$ & $\mathbf{J}$ & $\bar{K}$ & $\mathbf{L}$ & $\mathbf{M}$ & $\mathbf{N}$ & 0 & $\bar{\Sigma}$ & $\%$ \\
\hline 1.Altın Yunus Çeşme & $\checkmark$ & $\checkmark$ & $\sqrt{\checkmark}$ & $\bar{\varnothing}$ & $\sqrt{\checkmark}$ & $\sqrt{ }$ & $\sqrt{ }$ & $\sqrt{ }$ & $\bar{\varnothing}$ & $\sqrt{ }$ & $\checkmark$ & $\varnothing$ & 9 & 75 \\
\hline 2.Avrasya Petrol & $\varnothing$ & $\bar{\varnothing}$ & $\varnothing$ & $\varnothing$ & $\varnothing$ & $\bar{\varnothing}$ & $\varnothing$ & $\varnothing$ & $\varnothing$ & $\varnothing$ & $\varnothing$ & $\varnothing$ & 0 & 0 \\
\hline 3.Kuştur Kuşadası Tur. & $\varnothing$ & $\bar{\varnothing}$ & $\varnothing$ & $\varnothing$ & $\varnothing$ & $\bar{\varnothing}$ & $\varnothing$ & $\varnothing$ & $\varnothing$ & $\varnothing$ & $\varnothing$ & $\varnothing$ & 0 & 0 \\
\hline 4.Marmaris Altın Yun. & $\sqrt{\checkmark}$ & $\bar{\varnothing}$ & $\varnothing$ & $\varnothing$ & $\varnothing$ & $\bar{\varnothing}$ & $\varnothing$ & $\varnothing$ & $\varnothing$ & $\checkmark$ & $\varnothing$ & $\varnothing$ & 2 & 17 \\
\hline 5.Martı Otel & $\varnothing$ & $\bar{\varnothing}$ & $\varnothing$ & $\varnothing$ & $\varnothing$ & $\bar{\varnothing}$ & $\sqrt{ }$ & $\checkmark$ & $\varnothing$ & $\checkmark$ & $\varnothing$ & $\varnothing$ & 3 & 25 \\
\hline 6.Merit Turizm & $\bar{\varnothing}$ & $\bar{\varnothing}$ & $\varnothing$ & $\bar{\varnothing}$ & $\varnothing$ & $\bar{\varnothing}$ & $\bar{\varnothing}$ & $\checkmark$ & $\bar{\varnothing}$ & $\checkmark$ & $\varnothing$ & $\checkmark$ & 3 & 25 \\
\hline 7.Metemtur Turizm & $\varnothing$ & $\varnothing$ & $\varnothing$ & $\varnothing$ & $\varnothing$ & $\varnothing$ & $\varnothing$ & $\varnothing$ & $\varnothing$ & $\varnothing$ & $\varnothing$ & $\varnothing$ & 0 & 0 \\
\hline 8.Petrokent Turizm & $\bar{\varnothing}$ & $\bar{\varnothing}$ & $\varnothing$ & $\bar{\varnothing}$ & $\varnothing$ & $\bar{\varnothing}$ & $\bar{\varnothing}$ & $\varnothing$ & $\bar{\varnothing}$ & $\checkmark$ & $\bar{\varnothing}$ & $\bar{\varnothing}$ & 1 & 8 \\
\hline 9.Tek-Art Turizm & & & & & & & & & & & & & & \\
\hline 10.Ulaşlar Turizm & $\bar{\varnothing}$ & $\bar{\varnothing}$ & $\varnothing$ & $\bar{\varnothing}$ & $\varnothing$ & $\bar{\varnothing}$ & $\bar{\varnothing}$ & $\varnothing$ & $\bar{\varnothing}$ & $\varnothing$ & $\varnothing$ & $\bar{\varnothing}$ & 0 & 0 \\
\hline 11.Utopya Turizm & $\varnothing$ & $\varnothing$ & $\varnothing$ & $\varnothing$ & $\varnothing$ & $\varnothing$ & $\varnothing$ & 1 & $\varnothing$ & $\overline{1}$ & $\varnothing$ & $\varnothing$ & 2 & 17 \\
\hline
\end{tabular}

Tablodaki kodlamalar, E: Malzemeler, F: Enerji, G: Su, H: Biyolojik Çeşitlilik, I: Emisyonlar, I: Atık sular ve atıklar, J: Ürün ve hizmetler, K: Uyum, L: Nakliye, M: Genel, N: Tedarikçinin çevresel bakımdan değerlendirilmesi ve O: Çevresel şikâyet mekanizması şeklindedir.

BIST konaklama şirketlerini 2019 yılı faaliyet raporları sosyal unsurlar bağlamında incelenmesi sonucu şirketlerin bu unsurlara yer verme durumları Tablo 10'da belirtilmektedir. Tablo 10 incelendiğinde otuz sosyal unsurdan on dokuzunu karşıllayan Altın Yunus Çeşme Turistik Tesisler A.Ş.'nin yine ilk sırada olduğu görülmektedir. Sosyal unsurlar içerisinde en fazla yer verilenler "İstihdam" ve "İşgücü/ Yönetim İlişkileri" olurken; "Yerli Halkların Hakları", "Tedarikçilerin Toplum Üzerindeki Etkiler Bakımından Değerlendirilmesi" ile "Toplum Üzerindeki Şikayet Mekanizması" unsurlarına hiçbir şirketin yer vermediği görülmektedir. Şirketlerin sosyal unsurlara yer verme düzeyleri farklılık gösterse de Metemtur Otelcilik ve Turizm İşletmeleri A.Ş.otuz unsurdan sadece iki unsura yer vererek en kötü performansı göstermiştir. 
Tablo 10: BIST Konaklama Şirketlerinin 2019 Yılı Faaliyet Raporlarında Sosyal Unsurlara Yer Verme Düzeyleri

\begin{tabular}{|c|c|c|c|c|c|c|c|c|c|c|c|c|c|c|c|c|c|c|c|c|c|c|c|c|c|c|c|c|c|c|c|c|}
\hline \multirow{3}{*}{ Şirketler } & \multicolumn{30}{|c|}{ Sosyal Unsurlar } & & \\
\hline & \multicolumn{8}{|c|}{$\begin{array}{|lcc|}\text { Iş̧ Gücü Uygulamaları } & \text { ve } \\
\text { İnsana Yaraşır İş }\end{array}$} & \multicolumn{10}{|c|}{ İnsan Hakları } & \multicolumn{7}{|c|}{ Toplum } & \multicolumn{5}{|c|}{ Ürün Sorumluluğu } & \multicolumn{2}{|c|}{\begin{tabular}{|l|} 
Topla \\
m
\end{tabular}} \\
\hline & $A$ & B & C & D & $E$ & $F$ & G & $\mathrm{H}$ & I & i & $\mathbf{J}$ & $\mathrm{K}$ & $L$ & $M$ & $N$ & 0 & Ö & $P$ & $\mathbf{R}$ & $s$ & Ş & $T$ & $\mathbf{U}$ & Ü & $\mathbf{v}$ & $\mathbf{Y}$ & $z$ & $A_{1}$ & $B_{1}$ & $C_{1}$ & $\Sigma$ & $\%$ \\
\hline $\begin{array}{l}\text { 1.Altın } \\
\text { Çeşme }\end{array}$ & $\checkmark$ & $\checkmark$ & $\checkmark$ & $\checkmark$ & $\checkmark$ & $\checkmark$ & $\checkmark$ & $\checkmark$ & $\checkmark$ & $\checkmark$ & $\varnothing$ & e & $\varnothing$ & $\checkmark$ & $\varnothing$ & $\checkmark$ & $\varnothing$ & $\checkmark$ & $\varnothing$ & $\varnothing$ & $\checkmark$ & $\varnothing$ & $\checkmark$ & $\varnothing$ & $\varnothing$ & $\checkmark$ & $\checkmark$ & $\checkmark$ & $\varnothing$ & $\checkmark$ & 19 & 63 \\
\hline 2.Avrasya Petrol & $\checkmark$ & $\checkmark$ & $\varnothing$ & $\varnothing$ & $\varnothing$ & $\varnothing$ & $\varnothing$ & $\varnothing$ & $\varnothing$ & $\varnothing$ & $\varnothing$ & $\varnothing$ & $\varnothing$ & $\varnothing$ & $\varnothing$ & $\varnothing$ & $\varnothing$ & $\varnothing$ & $\varnothing$ & $\varnothing$ & $\checkmark$ & $\varnothing$ & $\varnothing$ & $\varnothing$ & $\varnothing$ & $\varnothing$ & $\varnothing$ & $\varnothing$ & $\varnothing$ & $\varnothing$ & 3 & 10 \\
\hline $\begin{array}{l}\text { 3.Kuştur Kuşadası } \\
\text { Tur. }\end{array}$ & $\checkmark$ & $\checkmark$ & $\varnothing$ & $\varnothing$ & $\varnothing$ & $\varnothing$ & $\varnothing$ & $\varnothing$ & $\varnothing$ & $\varnothing$ & $\varnothing$ & $\varnothing$ & $\varnothing$ & $\varnothing$ & $\varnothing$ & $\varnothing$ & $\varnothing$ & $\varnothing$ & $\varnothing$ & $\varnothing$ & $\varnothing$ & $\varnothing$ & $\varnothing$ & $\varnothing$ & $\varnothing$ & $\varnothing$ & $\checkmark$ & $\varnothing$ & $\varnothing$ & $\varnothing$ & 3 & 10 \\
\hline $\begin{array}{ll}\text { 4.Marmaris } & \text { Altın } \\
\text { Yun. } & \end{array}$ & $\checkmark$ & 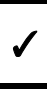 & $\checkmark$ & $\checkmark$ & $\checkmark$ & $\checkmark$ & $\varnothing$ & 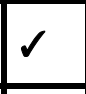 & $\checkmark$ & $\checkmark$ & $\checkmark$ & $\varnothing$ & $\varnothing$ & $\checkmark$ & $\varnothing$ & $\checkmark$ & $\varnothing$ & $\checkmark$ & $\varnothing$ & $\checkmark$ & $\checkmark$ & $\varnothing$ & $\varnothing$ & $\varnothing$ & $\varnothing$ & $\checkmark$ & $\checkmark$ & $\varnothing$ & $\varnothing$ & $\varnothing$ & 17 & 57 \\
\hline 5.Martı Otel & $\checkmark$ & $\checkmark$ & $\varnothing$ & $\checkmark$ & $\varnothing$ & $\varnothing$ & $\varnothing$ & $\varnothing$ & $e$ & 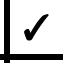 & $\checkmark$ & $\checkmark$ & $\checkmark$ & $\varnothing$ & $\varnothing$ & $\checkmark$ & $\varnothing$ & $\varnothing$ & $\varnothing$ & $\checkmark$ & $\checkmark$ & 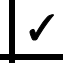 & $\varnothing$ & $\varnothing$ & $\varnothing$ & $\varnothing$ & 6 & & $\gamma$ & $\gamma$ & 12 & 40 \\
\hline 6.Mer & 1 & $\checkmark$ & $\checkmark$ & e & $\checkmark$ & $\checkmark$ & $\varnothing$ & 1 & $\checkmark$ & $\checkmark$ & 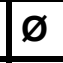 & $\varnothing$ & $\varnothing$ & $\checkmark$ & $\varnothing$ & $\checkmark$ & $\varnothing$ & $\varnothing$ & $\varnothing$ & $\checkmark$ & $\checkmark$ & $\checkmark$ & $\varnothing$ & $\varnothing$ & $\varnothing$ & $\varnothing$ & $\checkmark$ & $\checkmark$ & $\varnothing$ & $\checkmark$ & 15 & 50 \\
\hline 7.Metemtur Turizm & $\checkmark$ & $\checkmark$ & $\varnothing$ & 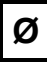 & $\varnothing$ & $\varnothing$ & $\varnothing$ & $\varnothing$ & $\varnothing$ & $\varnothing$ & $\varnothing$ & $\varnothing$ & $\varnothing$ & $\varnothing$ & $\varnothing$ & $\varnothing$ & $\varnothing$ & $\varnothing$ & $\varnothing$ & $\varnothing$ & $\varnothing$ & $\varnothing$ & $\varnothing$ & $\varnothing$ & $\varnothing$ & $\varnothing$ & $\varnothing$ & $\varnothing$ & $\varnothing$ & $\varnothing$ & 2 & 7 \\
\hline 8.Petrokent Turizm & 1 & $\checkmark$ & $\varnothing$ & $\checkmark$ & $\checkmark$ & $\checkmark$ & $\varnothing$ & $\varnothing$ & $\checkmark$ & $\checkmark$ & $\varnothing$ & $\varnothing$ & $\varnothing$ & $\varnothing$ & $\varnothing$ & $\checkmark$ & $\varnothing$ & $\varnothing$ & $\varnothing$ & $\varnothing$ & $\varnothing$ & $\varnothing$ & $\varnothing$ & $\varnothing$ & $\varnothing$ & $\varnothing$ & $\varnothing$ & $\varnothing$ & 1 & $\gamma$ & 9 & 30 \\
\hline 9.Tek-Art Turizm & & & & & & & & & & & & & & & & & & & & & & & & & & & & & & & & \\
\hline $10 . U$ & $\checkmark$ & 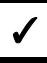 & $\varnothing$ & $\varnothing$ & $\varnothing$ & $\checkmark$ & $\varnothing$ & e & $\varnothing$ & $\varnothing$ & $\varnothing$ & $\varnothing$ & $\varnothing$ & $\varnothing$ & $\varnothing$ & $\varnothing$ & $\varnothing$ & $\varnothing$ & $\varnothing$ & $\varnothing$ & $\varnothing$ & $\varnothing$ & $\varnothing$ & $\varnothing$ & $\varnothing$ & $\varnothing$ & $\varnothing$ & $\varnothing$ & $\varnothing$ & $\varnothing$ & 3 & 10 \\
\hline 1.Utopya Turizm & $\checkmark$ & $\checkmark$ & $\varnothing$ & $\checkmark$ & $\varnothing$ & $\varnothing$ & $\varnothing$ & $\varnothing$ & $\checkmark$ & $\varnothing$ & $\varnothing$ & $x$ & $\varnothing$ & $\varnothing$ & $\varnothing$ & $\checkmark$ & $\varnothing$ & $\varnothing$ & $\varnothing$ & $\varnothing$ & $\varnothing$ & $\varnothing$ & $\varnothing$ & $\varnothing$ & $\varnothing$ & $\checkmark$ & $\checkmark$ & $\varnothing$ & $\varnothing$ & $\varnothing$ & 7 & 23 \\
\hline
\end{tabular}

Tablodaki kodlamalar; A: İstihdam, B: İşücü /Yönetim İlișkileri, C: İs Sağlığı ve güvenliği, D: Eğitim ve öğretim, E: Ceşitlilik ve fırsat eșitliği, F: Kadın erkek için eşit ücret G: Tedarikçinin işgücü uygulamaları bakımından değerlendirilmesi ve $\mathrm{H}$ : İ̧̧ gücü uygulamaları şikayet mekanizması, I: Yatırım, İ: Ayrımcılığın önlenmesi, J: Örgütlenme ve toplu sözleşme hakkı, K: Çocuk işçiler, L: Zorla veya cebren çalıştırma, M: Güvenlik uygulamaları, N: Yerli halkların hakları,

O:Değerlendirme, Ö:Tedarikçilerin insan hakları bakımından değerlendirilmesi, P: İnsan hakları șikayet mekanizması, R:Yerel Toplumlar, S:Yolsuzlukla mücadele, Ş:Kamu Politikası, T:Rekabete aykırı davranış, U:Uyum, Ü:Tedarikçilerin Toplum üzerindeki etkiler bakımından değerlendirilmesi, V:Toplum üzerindeki etkilere iliş̧in şikayet mekanizması, Y:Müşteri sağlığı ve güvenliği, Z:Ürün ve hizmet etiketlemesi, A1: Pazarlama iletişimi, B1: Müşteri gizliliği ve C1: Uyum şeklindedir. 


\subsection{BIST Konaklama Şirketlerinin 2017-2018 ve 2019 Yıllarına Ait Bulgularının Karşılaştırılması}

BIST' te işlem gören konaklama şirketlerinin 2017-2018 ve 2019 yıllarında ekonomik unsurlar çerçevesinde gerçekleştirilen ve raporlanan sürdürülebilirlik faaliyetlerine ait analiz bulgularının karşılaştırması Tablo 11'de sunulmuştur.

Tablo 11: BIST Konaklama Şirketlerinin 2017-2018 ve 2019 Yılı Faaliyet Raporlarında Ekonomik Unsurlara Yer Verme Düzeyleri

\begin{tabular}{|c|c|c|c|c|c|c|c|}
\hline \multirow{2}{*}{ Şirketler } & \multirow{2}{*}{ Yillar } & \multicolumn{4}{|c|}{ Ekonomik Unsurlar } & \multicolumn{2}{|c|}{ Toplam } \\
\hline & & $\mathbf{A}$ & $\mathbf{B}$ & $\mathbf{C}$ & $\mathbf{D}$ & $\sum$ & $\%$ \\
\hline \multirow{3}{*}{ 1.Altın Yunus Çeşme } & 2017 & $\checkmark$ & $\checkmark$ & $\checkmark$ & $\checkmark$ & 4 & 100 \\
\hline & 2018 & $\checkmark$ & $\checkmark$ & 2 & $\checkmark$ & 4 & 100 \\
\hline & 2019 & $\checkmark$ & $\checkmark$ & 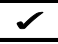 & $\checkmark$ & 4 & 100 \\
\hline \multirow{3}{*}{ 2.Avrasya Petrol } & 2017 & $\checkmark$ & $\varnothing$ & $\Omega$ & $\varnothing$ & 2 & 50 \\
\hline & 2018 & $\checkmark$ & $\varnothing$ & 2 & $\varnothing$ & 2 & 50 \\
\hline & 2019 & $\checkmark$ & $\checkmark$ & 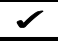 & $\varnothing$ & 3 & 75 \\
\hline \multirow{3}{*}{ 3.Kuştur Kuşadası Tur. } & 2017 & $\checkmark$ & $\varnothing$ & $\varnothing$ & $\varnothing$ & 1 & 25 \\
\hline & 2018 & $\checkmark$ & $\varnothing$ & $\varnothing$ & $\varnothing$ & 1 & 25 \\
\hline & 2019 & $\checkmark$ & $\varnothing$ & $\varnothing$ & $\varnothing$ & 1 & 25 \\
\hline \multirow{3}{*}{ 4. Marmaris Altın Yun. } & 2017 & $\checkmark$ & $\varnothing$ & 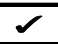 & $\varnothing$ & 2 & 50 \\
\hline & 2018 & $\checkmark$ & $\varnothing$ & 2 & $\varnothing$ & 2 & 50 \\
\hline & 2019 & $\checkmark$ & $\checkmark$ & 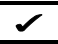 & $\varnothing$ & 3 & 75 \\
\hline \multirow{3}{*}{ 5.Martı Otel } & 2017 & $\checkmark$ & $\checkmark$ & 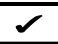 & $\varnothing$ & 3 & 75 \\
\hline & 2018 & $\checkmark$ & $\checkmark$ & 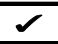 & $\varnothing$ & 3 & 75 \\
\hline & 2019 & $\checkmark$ & $\checkmark$ & 2 & $\varnothing$ & 3 & 75 \\
\hline \multirow{3}{*}{ 6.Merit Turizm } & 2017 & $\checkmark$ & $\checkmark$ & $\checkmark$ & $\varnothing$ & 3 & 75 \\
\hline & 2018 & $\checkmark$ & $\varnothing$ & $\checkmark$ & $\varnothing$ & 2 & 50 \\
\hline & 2019 & $\checkmark$ & $\checkmark$ & $\checkmark$ & $\varnothing$ & 3 & 75 \\
\hline \multirow{3}{*}{ 7.Metemtur Turizm } & 2017 & $\checkmark$ & $\varnothing$ & $\varnothing$ & $\varnothing$ & 1 & 25 \\
\hline & 2018 & $\checkmark$ & $\varnothing$ & $\varnothing$ & $\varnothing$ & 1 & 25 \\
\hline & 2019 & $\checkmark$ & $\varnothing$ & $\varnothing$ & $\varnothing$ & 1 & 25 \\
\hline \multirow{3}{*}{ 8.Petrokent Turizm } & 2017 & $\checkmark$ & $\varnothing$ & $\checkmark$ & $\varnothing$ & 2 & 50 \\
\hline & 2018 & $\checkmark$ & $\varnothing$ & $\checkmark$ & $\varnothing$ & 2 & 50 \\
\hline & 2019 & $\checkmark$ & $\varnothing$ & $\checkmark$ & $\varnothing$ & 2 & 50 \\
\hline \multirow{3}{*}{ 9.Tek-Art Turizm } & 2017 & $\checkmark$ & $\varnothing$ & $\checkmark$ & $\varnothing$ & 2 & 50 \\
\hline & 2018 & $\checkmark$ & $\varnothing$ & $\checkmark$ & $\varnothing$ & 2 & 50 \\
\hline & 2019 & & & & & & \\
\hline \multirow{3}{*}{ 10.Ulaşlar Turizm } & 2017 & $\checkmark$ & $\varnothing$ & $\varnothing$ & $\varnothing$ & 1 & 25 \\
\hline & 2018 & $\checkmark$ & $\varnothing$ & $\varnothing$ & $\varnothing$ & 1 & 25 \\
\hline & 2019 & $\checkmark$ & $\varnothing$ & $\varnothing$ & $\varnothing$ & 1 & 25 \\
\hline \multirow{3}{*}{ 11. Ütopya Turizm } & 2017 & $\checkmark$ & $\varnothing$ & $\checkmark$ & $\varnothing$ & 2 & 50 \\
\hline & 2018 & $\checkmark$ & $\varnothing$ & $\checkmark$ & $\varnothing$ & 2 & 50 \\
\hline & 2019 & $\checkmark$ & $\checkmark$ & $\checkmark$ & $\varnothing$ & 3 & 75 \\
\hline
\end{tabular}

Tablo 11 incelendiğinde BIST konaklama şirketlerinin 2017-2018 ve 2019 yıllarında ekonomik unsurlara faaliyet raporlarında yer vermek düzeylerinde büyük farklılıklar olmadığı ancak Avrasya Petrol ve Turistik Tesisler A.Ş., Marmaris Altın Yunus Turistik Tesisler A.Ş., ve Utopya Turizm İnşaat İşletmecilik Ticaret A.Ş.'nin 2019 yılında ekonomik unsurlara yer verme oranlarının arttığı görülmektedir. Merit Turizm Yatırım A.Ş., ise 2017 yılında faaliyet raporunda dört unsurdan üç unsura yer verirken, 2018 yılında iki unsura yer vermiş, 2019 yılında yeniden üç unsura yer vermiştir. 
Tablo 12: BIST Konaklama Şirketlerinin 2017-2018 ve 2019 Yılı Faaliyet Raporlarında Çevresel Unsurlara Yer Verme Düzeyleri

\begin{tabular}{|c|c|c|c|c|c|c|c|c|c|c|c|c|c|c|c|}
\hline & & \multicolumn{12}{|c|}{ Çevresel } & \multirow[b]{2}{*}{$\Sigma$} & \multirow[b]{2}{*}{$\%$} \\
\hline & & $\mathbf{E}$ & $\mathbf{F}$ & $\mathbf{G}$ & $\mathbf{H}$ & $\mathbf{I}$ & i & $\mathbf{J}$ & $\mathbf{K}$ & $\mathbf{L}$ & $\mathbf{M}$ & $\mathbf{N}$ & $\mathbf{O}$ & & \\
\hline \multirow{3}{*}{ 1.Altın Yunus Çeșme } & 2017 & $\checkmark$ & $\checkmark$ & $\checkmark$ & $\checkmark$ & $\checkmark$ & $\checkmark$ & $\checkmark$ & $\varnothing$ & $\checkmark$ & $\checkmark$ & $\varnothing$ & $\varnothing$ & 9 & 75 \\
\hline & 2018 & $\checkmark$ & $\checkmark$ & $\checkmark$ & $\varnothing$ & $\checkmark$ & $\checkmark$ & $\checkmark$ & $\checkmark$ & $\varnothing$ & $\checkmark$ & $\checkmark$ & $\varnothing$ & 9 & 75 \\
\hline & 2019 & $\checkmark$ & $\checkmark$ & $\checkmark$ & $\varnothing$ & $\checkmark$ & $\checkmark$ & $\checkmark$ & $\checkmark$ & $\varnothing$ & $\checkmark$ & $\checkmark$ & $\varnothing$ & 9 & 75 \\
\hline \multirow{3}{*}{ 2.Avrasya Petrol } & 2017 & $\varnothing$ & $\varnothing$ & $\varnothing$ & $\varnothing$ & $\varnothing$ & $\varnothing$ & $\varnothing$ & $\checkmark$ & $\varnothing$ & $\checkmark$ & $\varnothing$ & $\varnothing$ & 2 & 17 \\
\hline & 2018 & $\varnothing$ & $\varnothing$ & $\varnothing$ & $\varnothing$ & $\varnothing$ & $\varnothing$ & $\varnothing$ & $\varnothing$ & $\varnothing$ & $\varnothing$ & $\varnothing$ & $\varnothing$ & 0 & 0 \\
\hline & 2019 & $\varnothing$ & $\varnothing$ & $\varnothing$ & $\varnothing$ & $\varnothing$ & $\varnothing$ & $\varnothing$ & $\varnothing$ & $\varnothing$ & $\varnothing$ & $\varnothing$ & $\varnothing$ & 0 & 0 \\
\hline \multirow{3}{*}{ 3.Kuştur Kuşadası Tur. } & 2017 & $\checkmark$ & $\varnothing$ & $\varnothing$ & $\varnothing$ & $\varnothing$ & $\varnothing$ & $\varnothing$ & $\checkmark$ & $\varnothing$ & $\checkmark$ & $\varnothing$ & $\varnothing$ & 3 & 25 \\
\hline & 2018 & $\checkmark$ & $\varnothing$ & $\varnothing$ & $\varnothing$ & $\varnothing$ & $\varnothing$ & $\varnothing$ & $\checkmark$ & $\varnothing$ & $\checkmark$ & $\varnothing$ & $\varnothing$ & 3 & 25 \\
\hline & 2019 & $\varnothing$ & $\varnothing$ & $\varnothing$ & $\varnothing$ & $\varnothing$ & $\varnothing$ & $\varnothing$ & $\varnothing$ & $\varnothing$ & $\varnothing$ & $\varnothing$ & $\varnothing$ & 0 & 0 \\
\hline \multirow{3}{*}{ 4. Marmaris Altin Yun. } & 2017 & $\varnothing$ & $\varnothing$ & $\varnothing$ & $\varnothing$ & $\varnothing$ & $\varnothing$ & $\varnothing$ & $\checkmark$ & $\varnothing$ & $\checkmark$ & $\varnothing$ & $\varnothing$ & 2 & 17 \\
\hline & 2018 & $\varnothing$ & $\varnothing$ & $\varnothing$ & $\varnothing$ & $\varnothing$ & $\varnothing$ & $\varnothing$ & $\checkmark$ & $\varnothing$ & $\checkmark$ & $\varnothing$ & $\varnothing$ & 2 & 17 \\
\hline & 2019 & $\checkmark$ & $\varnothing$ & $\varnothing$ & $\varnothing$ & $\varnothing$ & $\varnothing$ & $\varnothing$ & $\varnothing$ & $\varnothing$ & $\checkmark$ & $\varnothing$ & $\varnothing$ & 2 & 17 \\
\hline \multirow{3}{*}{ 5. Martı Otel } & 2017 & $\varnothing$ & $\varnothing$ & $\varnothing$ & $\varnothing$ & $\varnothing$ & $\varnothing$ & $\varnothing$ & $\checkmark$ & $\varnothing$ & $\checkmark$ & $\varnothing$ & $\varnothing$ & 2 & 17 \\
\hline & 2018 & $\varnothing$ & $\varnothing$ & $\varnothing$ & $\varnothing$ & $\varnothing$ & $\varnothing$ & $\varnothing$ & $\checkmark$ & $\varnothing$ & $\checkmark$ & $\varnothing$ & $\varnothing$ & 2 & 17 \\
\hline & 2019 & $\varnothing$ & $\varnothing$ & $\varnothing$ & $\varnothing$ & $\varnothing$ & $\varnothing$ & $\checkmark$ & $\checkmark$ & $\varnothing$ & $\checkmark$ & $\varnothing$ & $\varnothing$ & 3 & 25 \\
\hline \multirow{3}{*}{ 6. Merit Turizm } & 2017 & $\varnothing$ & $\varnothing$ & $\varnothing$ & $\varnothing$ & $\varnothing$ & $\varnothing$ & $\varnothing$ & $\checkmark$ & $\varnothing$ & $\checkmark$ & $\varnothing$ & $\checkmark$ & 3 & 25 \\
\hline & 2018 & $\varnothing$ & $\varnothing$ & $\varnothing$ & $\varnothing$ & $\varnothing$ & $\varnothing$ & $\varnothing$ & $\varnothing$ & $\varnothing$ & $\varnothing$ & $\varnothing$ & $\varnothing$ & 0 & 0 \\
\hline & 2019 & $\varnothing$ & $\varnothing$ & $\varnothing$ & $\varnothing$ & $\varnothing$ & $\varnothing$ & $\varnothing$ & $\checkmark$ & $\varnothing$ & $\checkmark$ & $\varnothing$ & $\checkmark$ & 3 & 25 \\
\hline \multirow{3}{*}{ 7.Metemtur Turizm } & 2017 & $\varnothing$ & $\varnothing$ & $\varnothing$ & $\varnothing$ & $\varnothing$ & $\varnothing$ & $\varnothing$ & $\varnothing$ & $\varnothing$ & $\varnothing$ & $\varnothing$ & $\varnothing$ & 0 & 0 \\
\hline & 2018 & $\varnothing$ & $\varnothing$ & $\varnothing$ & $\varnothing$ & $\varnothing$ & $\varnothing$ & $\varnothing$ & $\varnothing$ & $\varnothing$ & $\varnothing$ & $\varnothing$ & $\varnothing$ & 0 & 0 \\
\hline & 2019 & $\varnothing$ & $\varnothing$ & $\varnothing$ & $\varnothing$ & $\varnothing$ & $\varnothing$ & $\varnothing$ & $\varnothing$ & $\varnothing$ & $\varnothing$ & $\varnothing$ & $\varnothing$ & 0 & 0 \\
\hline \multirow{3}{*}{ 8.Petrokent Turizm } & 2017 & $\varnothing$ & $\varnothing$ & $\varnothing$ & $\varnothing$ & $\varnothing$ & $\varnothing$ & $\varnothing$ & $\varnothing$ & $\varnothing$ & $\checkmark$ & $\varnothing$ & $\varnothing$ & 1 & 8 \\
\hline & 2018 & $\varnothing$ & $\varnothing$ & $\varnothing$ & $\varnothing$ & $\varnothing$ & $\varnothing$ & $\varnothing$ & $\varnothing$ & $\varnothing$ & $\checkmark$ & $\varnothing$ & $\varnothing$ & 1 & 8 \\
\hline & 2019 & $\varnothing$ & $\varnothing$ & $\varnothing$ & $\varnothing$ & $\varnothing$ & $\varnothing$ & $\varnothing$ & $\varnothing$ & $\varnothing$ & $\checkmark$ & $\varnothing$ & $\varnothing$ & 1 & 8 \\
\hline \multirow{3}{*}{ 9.Tek-Art Turizm } & 2017 & $\varnothing$ & $\varnothing$ & $\varnothing$ & $\varnothing$ & $\varnothing$ & $\varnothing$ & $\varnothing$ & $\checkmark$ & $\varnothing$ & $\checkmark$ & $\varnothing$ & $\varnothing$ & 2 & 17 \\
\hline & 2018 & $\varnothing$ & $\varnothing$ & $\varnothing$ & $\varnothing$ & $\varnothing$ & $\varnothing$ & $\varnothing$ & $\checkmark$ & $\varnothing$ & $\checkmark$ & $\varnothing$ & $\checkmark$ & 3 & 25 \\
\hline & 2019 & & & & & & & & & & & & & & \\
\hline \multirow{3}{*}{ 10.Ulaşlar Turizm } & 2017 & $\varnothing$ & $\varnothing$ & $\varnothing$ & $\varnothing$ & $\varnothing$ & $\varnothing$ & $\varnothing$ & $\varnothing$ & $\varnothing$ & $\varnothing$ & $\varnothing$ & $\varnothing$ & 0 & 0 \\
\hline & 2018 & $\varnothing$ & $\varnothing$ & $\varnothing$ & $\varnothing$ & $\varnothing$ & $\varnothing$ & $\varnothing$ & $\varnothing$ & $\varnothing$ & $\varnothing$ & $\varnothing$ & $\varnothing$ & 0 & 0 \\
\hline & 2019 & $\varnothing$ & $\varnothing$ & $\varnothing$ & $\varnothing$ & $\varnothing$ & $\varnothing$ & $\varnothing$ & $\varnothing$ & $\varnothing$ & $\varnothing$ & $\varnothing$ & $\varnothing$ & 0 & 0 \\
\hline \multirow{3}{*}{ 11.Utopya Turizm } & 2017 & $\varnothing$ & $\varnothing$ & $\varnothing$ & $\varnothing$ & $\varnothing$ & $\varnothing$ & $\varnothing$ & $\checkmark$ & $\varnothing$ & $\checkmark$ & $\varnothing$ & $\varnothing$ & 2 & 17 \\
\hline & 2018 & $\varnothing$ & $\varnothing$ & $\varnothing$ & $\varnothing$ & $\varnothing$ & $\varnothing$ & $\varnothing$ & $\checkmark$ & $\varnothing$ & $\checkmark$ & $\varnothing$ & $\varnothing$ & 2 & 17 \\
\hline & 2019 & $\varnothing$ & $\varnothing$ & $\varnothing$ & $\varnothing$ & $\varnothing$ & $\varnothing$ & $\varnothing$ & $\checkmark$ & $\varnothing$ & $\checkmark$ & $\varnothing$ & $\varnothing$ & 2 & 17 \\
\hline
\end{tabular}

BIST konaklama şirketlerinin 2017-2018 ve 2019 yıllarında faaliyet raporlarında çevresel unsurlara yer verme durumları Tablo 12'de belirtilmiştir. Altın Yunus Çeşme Turistik Tesisler A.Ş., Marmaris Altın Yunus Turistik Tesisler A.Ş., Petrokent Turizm A.Ş. , Ulaşlar Turizm Yatıım ve Dayanıkı Tüketim Malları ve Utopya Turizm İnşaat İşletmecilik Ticaret A.Ş. 2017,2018 ve 2019 yıllarında çevresel unsurlara yer verme oranları değişmezken; Avrasya Petrol ve Turistik Tesisler A.Ş. 2017 yılında dokuz unsura yer verdiği faaliyet raporunda, 2018 ve 2019 yıllarında hiçbir unsura yer vermediği görülmektedir.

Şirketlerin sürdürülebilirlik bağlamında 2017, 2018 ve 2019 yılı sosyal unsurlara yer verme düzeyleri Tablo 13'te verilmiştir. Şirketlerin sosyal unsurlara yer verme düzeylerinde büyük değişiklik olmadığı görülse de; Marmaris Altın Yunus Turistik Tesisler A.Ş. 2017 ve 2018 yıllarında otuz unsurdan yedi unsura yer vermiş, 2019 yılında ise artış göstererek on yedi unsura yer vermiştir. Merit Turizm Yatırım ve İşletme A.Ş. de 2017 yılında otuz unsurdan on dört unsura yer verirken 2018 yılında sadece bir unsura yer vermiş, 2019 yılında yeniden bu oranı yükselterek on beş unsura raporlarında yer vermiştir. Metemtur Otelcilik ve Turizm İşletmeleri A.Ş. ise 2017, 2018 ve 2019 yıllarında faaliyet raporlarında sadece iki unsura yer vererek herhangi bir değişiklik göstermemiştir. 
Tablo 13: BIST Konaklama Şirketlerinin 2017-2018 ve 2019 Yılı Faaliyet Raporlarında Sosyal Unsurlara Yer Verme Düzeyleri

\begin{tabular}{|c|c|c|c|c|c|c|c|c|c|c|c|c|c|c|c|c|c|c|c|c|c|c|c|c|c|c|c|c|c|c|c|c|c|}
\hline & & \multicolumn{30}{|c|}{ Sosyal } & & \multirow[b]{3}{*}{$\%$} \\
\hline & & \multicolumn{8}{|c|}{ iş Gücü Uygulamaları ve insana yaraşır iş } & \multicolumn{10}{|c|}{ İnsan Hakları } & \multicolumn{7}{|c|}{ Toplum } & \multicolumn{5}{|c|}{ Ürün Sorumluluğu } & & \\
\hline & & $\mathbf{A}$ & B & $\begin{array}{ll}\mathrm{C} \\
\end{array}$ & \begin{tabular}{|l|}
$\mathbf{D}$ \\
\end{tabular} & $\mathbf{E}$ & $\mathbf{F}$ & G & $\mathrm{H}$ & $I$ & $i$ & \begin{tabular}{|l|}
$\mathrm{J}$ \\
\end{tabular} & $\mathbf{K}$ & $\mathbf{L}$ & $\mathbf{M}$ & \begin{tabular}{|l|}
$\mathrm{N}$ \\
\end{tabular} & \begin{tabular}{|l|}
0 \\
\end{tabular} & 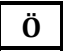 & $\mathbf{P}$ & $\mathbf{R}$ & $\mathbf{s}$ & \begin{tabular}{|l|}
$\mathbf{s}$ \\
\end{tabular} & \begin{tabular}{|l}
$\mathrm{T}$ \\
\end{tabular} & $\mathbf{U}$ & $\ddot{\mathrm{u}}$ & $\mathbf{V}$ & $\mathrm{Y}$ & \begin{tabular}{|l|l|}
$\mathrm{z}$ \\
\end{tabular} & $A_{1}$ & $B_{1}$ & $\mathrm{C}_{1}$ & $\Sigma$ & \\
\hline \multirow{3}{*}{ 1.Altın Yunus Çeşme } & 2017 & $\bar{v}$ & $\checkmark$ & $\bar{v}$ & $\checkmark$ & $\bar{v}$ & $\sqrt{ }$ & $\varnothing$ & $\checkmark$ & $\checkmark$ & $\checkmark$ & $\varnothing$ & $\varnothing$ & $\varnothing$ & $\bar{v}$ & $\varnothing$ & $\begin{array}{ll} \\
\end{array}$ & $\varnothing$ & $\checkmark$ & $\varnothing$ & $\varnothing$ & $\bar{v}$ & $\varnothing$ & $\checkmark$ & $\emptyset$ & $\emptyset$ & $\varnothing$ & $\checkmark$ & $\checkmark$ & $\begin{array}{lll} \\
\end{array}$ & 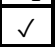 & 18 & 60 \\
\hline & 2018 & $\checkmark$ & $\sqrt{ }$ & $\checkmark$ & $\checkmark$ & $\checkmark$ & 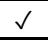 & $\varnothing$ & $\varnothing$ & $\checkmark$ & $\checkmark$ & $\varnothing$ & $\varnothing$ & $\varnothing$ & $\checkmark$ & $\varnothing$ & $\checkmark$ & $\varnothing$ & $\checkmark$ & $\varnothing$ & $\varnothing$ & $\checkmark$ & $\varnothing$ & $\checkmark$ & $\varnothing$ & $\varnothing$ & $\varnothing$ & $\checkmark$ & $\checkmark$ & $\checkmark$ & $\checkmark$ & 17 & 57 \\
\hline & 2019 & $\checkmark$ & & 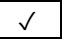 & $\checkmark$ & $\checkmark$ & & $\checkmark$ & $\checkmark$ & $\checkmark$ & 4 & $\varnothing$ & $\varnothing$ & a & 4 & $\varnothing$ & $\checkmark$ & $\varnothing$ & & $\emptyset$ & $\varnothing$ & $\checkmark$ & $\varnothing$ & & $\varnothing$ & $\emptyset$ & $\checkmark$ & $\checkmark$ & & & & 19 & 63 \\
\hline \multirow{3}{*}{ 2.Avrasya Petrol } & 2017 & $\sqrt{ }$ & $\checkmark$ & $\bar{v}$ & $\bar{v}$ & $\bar{v}$ & $\varnothing$ & $\varnothing$ & $\varnothing$ & $\varnothing$ & 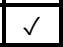 & 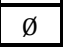 & 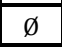 & $\bar{\varnothing}$ & $\sqrt{4}$ & $\varnothing$ & $\checkmark$ & $\varnothing$ & $\varnothing$ & $\emptyset$ & $\emptyset$ & $\varnothing$ & $\varnothing$ & $\bar{v}$ & $\emptyset$ & $\emptyset$ & $\varnothing$ & $\varnothing$ & $\varnothing$ & $\varnothing$ & $\varnothing$ & 9 & 30 \\
\hline & 2018 & $\checkmark$ & $\checkmark$ & $\varnothing$ & $\varnothing$ & $\varnothing$ & $\emptyset$ & $\varnothing$ & $\varnothing$ & $\emptyset$ & $\varnothing$ & $\varnothing$ & $\varnothing$ & $\varnothing$ & $\varnothing$ & $\varnothing$ & $\varnothing$ & $\varnothing$ & $\varnothing$ & $\varnothing$ & $\emptyset$ & \begin{tabular}{|l|l|}
$v$ \\
\end{tabular} & \begin{tabular}{|l|l|}
$\varnothing$ & \\
\end{tabular} & $\varnothing$ & $\varnothing$ & $\varnothing$ & $\varnothing$ & $\varnothing$ & $\varnothing$ & $\varnothing$ & $\varnothing$ & 3 & 10 \\
\hline & 119 & 4 & $\bar{v}$ & $\varnothing$ & $\varnothing$ & $\varnothing$ & $\varnothing$ & $\varnothing$ & $\varnothing$ & 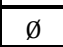 & $\varnothing$ & $=$ & - & - & 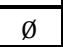 & $\varnothing$ & $\varnothing$ & , & $\varnothing$ & $\varnothing$ & $\emptyset$ & $\checkmark \checkmark$ & $\varnothing$ & $\varnothing$ & $\varnothing$ & $\varnothing$ & $\varnothing$ & $\varnothing$ & $\varnothing$ & $\varnothing$ & $\varnothing$ & 3 & 10 \\
\hline \multirow{3}{*}{ 3.Kuştur Kuşadası Tur. } & 2017 & $\checkmark$ & I & $\varnothing$ & $\checkmark$ & $\varnothing$ & $\varnothing$ & $\varnothing$ & $\varnothing$ & $\checkmark$ & $\checkmark$ & $\varnothing$ & $\varnothing$ & 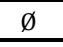 & $\varnothing$ & $\varnothing$ & $\checkmark$ & $\varnothing$ & $\varnothing$ & $\emptyset$ & $\emptyset$ & $\checkmark$ & $\varnothing$ & $\checkmark$ & $\emptyset$ & $\varnothing$ & $\varnothing$ & $\checkmark$ & $\varnothing$ & $\varnothing$ & $\checkmark$ & 10 & 33 \\
\hline & 2018 & $\checkmark$ & $\mathrm{v}$ & $\varnothing$ & $\checkmark$ & $\varnothing$ & $\varnothing$ & $\varnothing$ & $\varnothing$ & 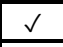 & \begin{tabular}{|l|l|} 
\\
\end{tabular} & $\varnothing$ & $\varnothing$ & $\varnothing$ & $\varnothing$ & $\varnothing$ & $\checkmark$ & $\varnothing$ & $\varnothing$ & $\varnothing$ & $\emptyset$ & $\checkmark$ & $\varnothing$ & $\checkmark$ & $\varnothing$ & $\varnothing$ & $\varnothing$ & $\checkmark$ & $\varnothing$ & $\varnothing$ & $\checkmark$ & 10 & 33 \\
\hline & 201 & $\checkmark$ & v & $\varnothing$ & $\emptyset$ & $\varnothing$ & $\bar{l}$ & $\varnothing$ & $\varnothing$ & $\varnothing$ & 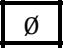 & $\varnothing$ & & $\bar{\varnothing}$ & $\bar{l}$ & - & $\varnothing$ & $\varnothing$ & & $\bar{x}$ & $\varnothing$ & $\varnothing$ & \begin{tabular}{|l|}
$\varnothing$ \\
\end{tabular} & $\varnothing$ & $\bar{\phi}$ & $\varnothing$ & $\varnothing$ & $\checkmark$ & $\varnothing$ & $\varnothing$ & $\varnothing$ & 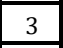 & 10 \\
\hline \multirow{3}{*}{ 4. Marmaris Altn Yun. } & 2017 & $\checkmark$ & & $\checkmark$ & $\checkmark$ & $\varnothing$ & $\ell$ & $\infty$ & $\varnothing$ & $\varnothing$ & $\checkmark$ & $\infty$ & $\infty$ & $\varnothing$ & $\varnothing$ & $\varnothing$ & $\checkmark$ & $\varnothing$ & $\bar{v}$ & $\varnothing$ & $\emptyset$ & $\varnothing$ & $\varnothing$ & 0 & $\varnothing$ & $\varnothing$ & $\varnothing$ & $\emptyset$ & $\varnothing$ & $\varnothing$ & $\varnothing$ & 7 & 23 \\
\hline & 2018 & $\bar{v}$ & $\bar{v}$ & $\bar{v}$ & $\bar{s}$ & $\varnothing$ & $\varnothing$ & $\varnothing$ & $\varnothing$ & $\varnothing$ & $\bar{v}$ & $\varnothing$ & $\varnothing$ & $\underline{\varnothing}$ & 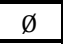 & $\bar{\alpha}$ & 4 & $\varnothing$ & & $\emptyset$ & $\emptyset$ & $\varnothing$ & $\varnothing$ & $\emptyset$ & $\varnothing$ & $\emptyset$ & $\varnothing$ & $\varnothing$ & $\varnothing$ & $\varnothing$ & $\varnothing$ & 7 & 23 \\
\hline & 19 & $\sqrt{v}$ & $\checkmark$ & $\checkmark$ & $\checkmark$ & $\checkmark$ & $\sqrt{ }$ & $\varnothing$ & $\checkmark$ & $\mathrm{v}$ & $\checkmark$ & $\checkmark$ & $\varnothing$ & $\varnothing$ & $\checkmark$ & $\varnothing$ & $\checkmark$ & $\varnothing$ & $\checkmark$ & $\varnothing$ & $\checkmark$ & $\checkmark$ & $\varnothing$ & $\varnothing$ & $\emptyset$ & $\emptyset$ & v & $v$ & $\varnothing$ & $\varnothing$ & $\varnothing$ & 17 & 57 \\
\hline \multirow{3}{*}{ 5.Mart Otel } & 2017 & $\bar{v}$ & $\sqrt{ }$ & $\varnothing$ & $\checkmark$ & $\varnothing$ & $\bar{v}$ & $\bar{\alpha}$ & $\varnothing$ & - & $\checkmark$ & $v$ & $\sqrt{ }$ & $v$ & $x_{x}$ & $\checkmark$ & $\bar{v}$ & e & $\varnothing$ & $\varnothing$ & $\varnothing$ & $\varnothing$ & $\varnothing$ & $\checkmark$ & $\varnothing$ & $\emptyset$ & $\varnothing$ & $\sqrt{v}$ & $\varnothing$ & $\varnothing$ & $\checkmark$ & 16 & 53 \\
\hline & 20 & $\checkmark$ & $\checkmark$ & $\varnothing$ & $\begin{array}{lll} \\
\end{array}$ & $\varnothing$ & $\varnothing$ & $\varnothing$ & $\varnothing$ & $\checkmark$ & $\checkmark$ & $\checkmark$ & $\checkmark$ & $\checkmark$ & $\varnothing$ & \begin{tabular}{|l|} 
\\
\end{tabular} & $\checkmark$ & $\varnothing$ & $\emptyset$ & $\checkmark$ & $\checkmark$ & $\varnothing$ & $\varnothing$ & $\checkmark$ & $\emptyset$ & $\emptyset$ & $\varnothing$ & $\checkmark$ & $\varnothing$ & $\emptyset$ & $\checkmark$ & 15 & 50 \\
\hline & 2019 & 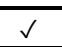 & - & $\varnothing$ & $\checkmark$ & $\varnothing$ & $\varnothing$ & $\varnothing$ & $\varnothing$ & 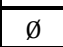 & 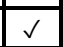 & $\checkmark$ & 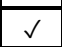 & - & $\varnothing$ & $\varnothing$ & $\checkmark$ & $\varnothing$ & $\varnothing$ & $\varnothing$ & $\checkmark$ & $\begin{array}{ll} \\
\end{array}$ & 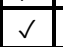 & $\varnothing$ & 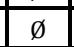 & $\emptyset$ & $\varnothing$ & $\checkmark$ & $\varnothing$ & $\varnothing$ & $\varnothing$ & 12 & 40 \\
\hline \multirow{3}{*}{ 6.Merit Turizm } & & $\checkmark$ & $\checkmark$ & $\varnothing$ & $\varnothing$ & $\checkmark$ & $\checkmark$ & $\varnothing$ & $\sqrt{v}$ & $\checkmark$ & $\checkmark$ & $\varnothing$ & $\varnothing$ & $\emptyset$ & $\checkmark$ & $\varnothing$ & $\checkmark$ & $\varnothing$ & $\checkmark$ & $\varnothing$ & $\varnothing$ & $\checkmark$ & $\varnothing$ & $\checkmark$ & $\emptyset$ & $\emptyset$ & $\varnothing$ & $\checkmark$ & $\phi$ & $\varnothing$ & $\checkmark$ & 14 & 47 \\
\hline & 2018 & $\varnothing$ & $\varnothing$ & $\varnothing$ & $\varnothing$ & $\varnothing$ & $\varnothing$ & $\varnothing$ & $\varnothing$ & $\varnothing$ & $\varnothing$ & $\varnothing$ & $\varnothing$ & $\varnothing$ & $\varnothing$ & $\varnothing$ & $\varnothing$ & $\varnothing$ & $\varnothing$ & $\varnothing$ & $\varnothing$ & $\varnothing$ & $\varnothing$ & $\varnothing$ & $\emptyset$ & $\emptyset$ & $\varnothing$ & $\checkmark$ & $\varnothing$ & $\varnothing$ & $\varnothing$ & 1 & 3 \\
\hline & 2019 & $\bar{v}$ & $\checkmark$ & $\checkmark$ & $\varnothing$ & $\bar{v}$ & $\checkmark$ & $\varnothing$ & 4 & - & $\bar{v}$ & $\varnothing$ & $\emptyset$ & $\bar{\varnothing}$ & $\checkmark$ & $\varnothing$ & $\checkmark$ & $\emptyset$ & & $\varnothing$ & $\checkmark$ & $\checkmark$ & $\checkmark$ & $\varnothing$ & $\emptyset$ & $\emptyset$ & $\varnothing$ & $\checkmark$ & $\sqrt{ }$ & $\varnothing$ & 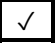 & 15 & 50 \\
\hline \multirow{3}{*}{ 7.Metemtur Turizm } & 20 & $\bar{v}$ & $\bar{v}$ & $\varnothing$ & $\varnothing$ & $\varnothing$ & 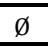 & $\varnothing$ & $\varnothing$ & $\varnothing$ & $\infty$ & $\infty$ & $\varnothing$ & $\bar{\varnothing}$ & $\infty$ & $\varnothing$ & $\varnothing$ & $\varnothing$ & $\emptyset$ & $\emptyset$ & $\emptyset$ & $\varnothing$ & $\varnothing$ & $\varnothing$ & $\emptyset$ & $\emptyset$ & $\varnothing$ & $\varnothing$ & $\varnothing$ & $\varnothing$ & $\varnothing$ & 2 & 7 \\
\hline & 2018 & $\checkmark$ & $\sqrt{ }$ & $\varnothing$ & $\varnothing$ & $\varnothing$ & $\varnothing$ & $\emptyset$ & $\varnothing$ & $\varnothing$ & 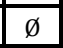 & - & $\varnothing$ & $\varnothing$ & - & $\varnothing$ & $\varnothing$ & $\emptyset$ & $\varnothing$ & $\emptyset$ & $\varnothing$ & $\varnothing$ & \begin{tabular}{|l|l|}
$\varnothing$ & \\
\end{tabular} & $\varnothing$ & $\emptyset$ & $\emptyset$ & $\varnothing$ & $\varnothing$ & $\varnothing$ & $\varnothing$ & $\varnothing$ & 2 & 7 \\
\hline & 2019 & $\bar{v}$ & $\bar{v}$ & $\varnothing$ & $\varnothing$ & $\varnothing$ & 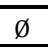 & - & $\varnothing$ & $\varnothing$ & 0 & $\varnothing$ & $\varnothing$ & $\varnothing$ & $\varnothing$ & $\varnothing$ & $\varnothing$ & $\varnothing$ & $\varnothing$ & $\varnothing$ & $\varnothing$ & $\varnothing$ & $\varnothing$ & $\varnothing$ & $\varnothing$ & $\varnothing$ & $\varnothing$ & $\varnothing$ & $\varnothing$ & $\varnothing$ & $\varnothing$ & 2 & 7 \\
\hline & 20 & $\checkmark$ & $\checkmark$ & $\varnothing$ & $\checkmark$ & $\checkmark$ & 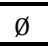 & $\varnothing$ & $\checkmark$ & $\varnothing$ & $\checkmark$ & $\varnothing$ & $\varnothing$ & , & 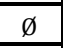 & $\varnothing$ & $\begin{array}{lllll}\checkmark & & \\
\end{array}$ & $\varnothing$ & 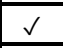 & $\varnothing$ & $\varnothing$ & $\varnothing$ & \begin{tabular}{|l|}
$\varnothing$ \\
\end{tabular} & $\varnothing$ & $\emptyset$ & $\varnothing$ & $\varnothing$ & $\varnothing$ & $\varnothing$ & $\varnothing$ & 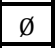 & \begin{tabular}{|l|}
8 \\
\end{tabular} & 27 \\
\hline 8.Petrokent Turizm & 2018 & $\checkmark$ & $\checkmark$ & $\varnothing$ & $\checkmark$ & $\checkmark$ & $\varnothing$ & $\varnothing$ & $\varnothing$ & $\varnothing$ & $\checkmark$ & $\varnothing$ & $\varnothing$ & $\varnothing$ & $\varnothing$ & $\varnothing$ & $\checkmark$ & $\emptyset$ & $\checkmark$ & $\varnothing$ & $\emptyset$ & $\varnothing$ & $\varnothing$ & $\varnothing$ & $\varnothing$ & $\emptyset$ & $\varnothing$ & $\varnothing$ & $\varnothing$ & $\varnothing$ & $\varnothing$ & 7 & 23 \\
\hline & 2019 & $\bar{v}$ & $\bar{v}$ & $\varnothing$ & $\sqrt{v}$ & $\bar{v}$ & $\bar{v}$ & - & $\varnothing$ & $\checkmark$ & 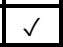 & $\varnothing$ & $\varnothing$ & $\bar{\varphi}$ & $\bar{l}$ & 6 & $\checkmark$ & $\varnothing$ & 8 & $\varnothing$ & $\varnothing$ & $\varnothing$ & $\varnothing$ & $\varnothing$ & $\emptyset$ & $\emptyset$ & $\varnothing$ & $\varnothing$ & $\varnothing$ & $\begin{array}{lll} & \\
\end{array}$ & $\varnothing$ & 9 & 30 \\
\hline & 2017 & $\checkmark$ & $\varnothing$ & $\checkmark$ & $\checkmark$ & $\checkmark$ & $x$ & $\infty$ & $\varnothing$ & 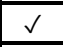 & $\checkmark$ & $\infty$ & $\infty$ & $\infty$ & 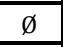 & $\checkmark$ & $\checkmark$ & $\varnothing$ & $\checkmark$ & $\checkmark$ & $\varnothing$ & $\varnothing$ & $\varnothing$ & $\checkmark$ & $\varnothing$ & $\varnothing$ & $\varnothing$ & $\varnothing$ & $\varnothing$ & $\varnothing$ & $\emptyset$ & 11 & 37 \\
\hline 9.Tek-Art Turizm & 26 & $\checkmark$ & $\varnothing$ & $\checkmark$ & $\checkmark$ & $\checkmark$ & $\varnothing$ & $\varnothing$ & $\varnothing$ & $\checkmark$ & 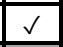 & $\varnothing$ & $\varnothing$ & $\varnothing$ & $\emptyset$ & $\checkmark$ & $\checkmark$ & $\varnothing$ & $\checkmark$ & $\sqrt{v}$ & $\varnothing$ & $\varnothing$ & $\varnothing$ & $\checkmark$ & $\varnothing$ & $\emptyset$ & $\varnothing$ & $\varnothing$ & $\varnothing$ & $\varnothing$ & $\emptyset$ & 11 & 37 \\
\hline & 2019 & & & & & & & & & & & & & & & & & & & & & & & & & & & & & & & & \\
\hline & 2017 & $\bar{v}$ & $\checkmark$ & $\varnothing$ & $\varnothing$ & $\varnothing$ & $\varnothing$ & $\varnothing$ & $\varnothing$ & $\varnothing$ & $\varnothing$ & $\varnothing$ & $\varnothing$ & $\infty$ & $\varnothing$ & $\varnothing$ & $\varnothing$ & $\varnothing$ & $\varnothing$ & $\emptyset$ & $\varnothing$ & $\varnothing$ & $\varnothing$ & $\varnothing$ & $\emptyset$ & $\varnothing$ & $\varnothing$ & $\varnothing$ & $\varnothing$ & $\varnothing$ & $\varnothing$ & 2 & 7 \\
\hline 10.Ulaşlar Turizm & & $\checkmark$ & $\checkmark$ & $\varnothing$ & $\varnothing$ & $\emptyset$ & $\theta$ & $\varnothing$ & $\varnothing$ & $\varnothing$ & $\emptyset$ & $\emptyset$ & $\varnothing$ & $\varnothing$ & $\varnothing$ & 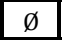 & $\infty$ & $\emptyset$ & $\varnothing$ & $\emptyset$ & $\emptyset$ & $\varnothing$ & $\varnothing$ & $\infty$ & $\emptyset$ & $\emptyset$ & $\varnothing$ & $\checkmark \mid$ & $\varnothing$ & $\emptyset$ & $\varnothing$ & 3 & 10 \\
\hline & 2019 & 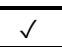 & $\checkmark$ & $\varnothing$ & $\varnothing$ & $\varnothing$ & $\checkmark$ & $\varnothing$ & $\varnothing$ & $\varnothing$ & $\varnothing$ & $\varnothing$ & $\varnothing$ & $\varnothing$ & $\varnothing$ & $\varnothing$ & $\varnothing$ & $\varnothing$ & $\varnothing$ & $\varnothing$ & $\varnothing$ & $\varnothing$ & $\varnothing \mid$ & $\varnothing$ & $\varnothing$ & $\emptyset$ & $\varnothing$ & $\varnothing$ & $\varnothing$ & $\varnothing$ & $\varnothing$ & 3 & 10 \\
\hline & 20 & $\varnothing$ & $\bar{v}$ & $\varnothing$ & $v$ & $\varnothing$ & $\infty$ & $\varnothing$ & $\varnothing$ & $\sqrt{ }$ & $\varnothing$ & 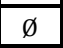 & $\varnothing$ & $\varnothing$ & $\phi$ & $\varnothing$ & $\begin{array}{ll} \\
\end{array}$ & $\varnothing$ & $\varnothing$ & $\varnothing$ & $\emptyset$ & $\checkmark$ & $\varnothing$ & $\varnothing$ & $\varnothing$ & $\emptyset$ & $\varnothing$ & $\checkmark$ & $\varnothing$ & $\varnothing$ & 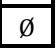 & 6 & 20 \\
\hline 11.Utopya Turizm & 201 & $\varnothing$ & - & $\varnothing$ & $\checkmark$ & $\varnothing$ & - & $\varnothing$ & $\varnothing$ & $\checkmark$ & $\varnothing$ & $\varnothing$ & $\varnothing$ & $\varnothing$ & $\varnothing$ & $\varnothing$ & $\checkmark$ & $\varnothing$ & $\varnothing$ & $\emptyset$ & $\varnothing$ & \begin{tabular}{|l|l|} 
& \\
\end{tabular} & $\varnothing$ & $\varnothing$ & $\emptyset$ & $\emptyset$ & $\varnothing$ & \begin{tabular}{|l|l}
$\checkmark$ \\
\end{tabular} & $\varnothing$ & $\varnothing$ & $\varnothing$ & 6 & 20 \\
\hline & 2019 & $\checkmark$ & $\checkmark$ & $\varnothing$ & $\checkmark$ & $\varnothing$ & $\varnothing$ & $\varnothing$ & $\varnothing$ & $\checkmark$ & $\varnothing$ & $\varnothing$ & $\varnothing$ & 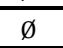 & $\varnothing$ & $\varnothing$ & $\checkmark$ & $\varnothing$ & $\varnothing$ & $\varnothing$ & $\varnothing$ & $\varnothing$ & $\varnothing$ & $\emptyset$ & $\varnothing$ & $\varnothing$ & v & I & $\varnothing$ & $\varnothing$ & $\varnothing$ & 7 & 23 \\
\hline
\end{tabular}




\section{Sonuç}

Dünya nüfusunun hızla artması, kentleşme ve sanayinin gelişmesi ile birlikte dünya üzerinde var olan doğal kaynaklar, bilinçsiz kullanım sonucunda insan ihtiyaçlarının karşılanmasında yetersiz kalarak hızla tükenmeye başlamıştır. Kaynakların sadece günümüz için değil gelecek nesillerin de faydalanabileceği şekilde tüketilmesi ve sürekliliğinin sağlanması gerekmektedir.

Ekonomik kalkınmanın önemli bir aracı olan turizm sektörü, doğal kaynaklar ile doğrudan bağlantılı olduğundan, kaynakların verimli kullanılması ve tahribatların önlenmesi turizmin sürdürülebilirliği açısından son derece önemlidir. Turizm sektörü, sürdürülebilirlik ile ilgili faaliyetleri göz ardı etmesi durumunda, hızla artan dünya nüfusu ve tükenen doğal kaynaklar karşısında etkilenecek sektörlerin başında gelmektedir. Üretim aşamasında emeğin yoğun olduğu turizm sektöründe insan vazgeçilmez bir unsurdur. Dolayısıyla sektörde sürdürülebilirliğin sağlanması insan faktörüne bağlıdır. Sürdürülebilirlik bilincine sahip tüm paydaşlar, turizm veya diğer tüm sektörlerde kullanılan kaynakların zarar görmemesi, korunması ve gelecek kuşaklara aktarılmasının sağlanması açısından önemli rol üstlenmektedirler. Turizmin sürdürülebilir olabilmesi ve bu doğrultuda gelişebilmesi için, tüm paydaşların bilinçli bir şekilde katıım sağlaması gerekir. Çünkü sürdürülebilirliğin sağlanabilmesi süreklilik arz eden bir durumdur.

Sürdürülebilirlik ile ilgili literatür incelendiğinde, kavramın öneminin kavrandığı ilk zamanlarda genel anlamı ile sürdürülebilirlik, sürdürülebilir kalkınma ve sürdürülebilir turizm bağlamında teorik çalışmaların gerçekleştirildiği gözlemlenmiştir. Son yıllarda ise araştırmalar, şirketlerin yayınlamış oldukları raporlar doğrultusunda göstermiş oldukları sürdürülebilirlik faaliyetlerinin ortaya konması, GRI ilkelerine göre raporlanması ve ölçümlenmesi üzerine yoğunlaştığı görülmektedir. Literatür taraması sonucunda elde edilen bulgular doğrultusunda şirketlerin gerek faaliyet raporlarında gerekse sürdürülebilirlik raporlarında göstermiş oldukları çevresel, ekonomik ve sosyal faaliyetlerini ayrıntılı bir şekilde paydaşları ile paylaşmaya başlamış, bu da sürdürülebilirliğe verdikleri önemin ölçümlenmesine olanak sağlamıştır. Gerçekleştirilen araştırmalarda sürdürülebilirlik raporu hazırlayan şirketlerin birçoğunun özellikle kolay ve anlaşılır olmasından kaynaklı olarak genel anlamda GRI ilkelerini kullandıkları görülmüştür. Bu bağlamda turizm sektöründe gerçekleştirilen araştırmaların incelenmesi sonucunda genel itibari ile sürdürülebilirliği sağlamak adına önerilerde bulunulduğu, raporlama bazında ise büyük oranda GRI ilkelerinin kullanıldığı görülmüştür.

$\mathrm{Bu}$ araştırmada, BIST' te işlem gören 11 adet konaklama şirketinin sürdürülebilirlik bağlamında göstermiş oldukları faaliyetlerin ve bu faaliyetlerin raporlanma düzeyinin analiz edilmesi amaçlanmıştır. Bu amaçla BIST konaklama şirketlerinin yayınlamış oldukları faaliyet raporlarında yer alan bilgilerin GRI ilkelerine uygun olarak ekonomik, sosyal ve çevresel faktörler bağlamında incelenerek, konaklama şirketlerinin sürdürülebilirlik bağlamında duyarlılıkları, gösterdiği faaliyetler ve yeterlilik düzeyleri içerik analizi ile karşılaştırmalı olarak saptanmaya çalışıımıştır. Analiz sürecinde BIST'te işlem gören 11 konaklama şirketinin 2017, 2018 ve 2019 yıllarına ait herhangi bir sürdürülebilirlik raporu bulunmadığından ilgili yıllarda yayımlanmış olan faaliyet raporları incelenmiştir. GRI ilkeleri doğrultusunda şirketlerin göstermiş oldukları faaliyetler, ekonomik, sosyal ve çevresel 46 unsur çerçevesinde analiz edilerek elde edilen bulgular hem yıl hemde şirket temelinde karşılaştırmalı olarak ortaya konmaya çalışıımıştır.

BIST konaklama şirketlerinin 2017 yılı faaliyet raporları incelendiğinde, ekonomik faktörler başlığı altında belirlenen 4 unsura yer veren tek şirketin Altın Yunus Çeşme Turistik Tesisler A.Ş olduğu, diğer şirketlerin birçoğunun bir veya iki unsura yer vererek oldukça sınırlı bilgi paylaştıkları görülmüştür. Çevresel faktörler bağlamında ise konaklama şirketlerinde özellikle çevre ile ilgili bilgilerin oldukça yüzeysel kaldığı, genel bir ifade ile yer verildiği saptanmıştır. Çevresel bağlamda toplam 12 unsur bulunmaktadır ve BIST'te işlem gören konaklama 
şirketlerinden sadece Altın Yunus Çeşme Turistik Tesisler A.Ş. 12 unsurdan 9'una faaliyet raporunda yer vermiştir. Diğer şirketlerin ise çevresel unsurlara yer verme oranı oldukça düşük olup en fazla 3 unsura yer verildiği görülmüştür. Sosyal bağlamda ise genel unsurlara yer verildiği, insan hakları, toplum, iş gücü uygulamaları ve ürün sorumluluğu ile ilgili oldukça yetersiz bilgi paylaşıldığı görülmüştür. 2017 yılında sosyal faktörler başlığı altında belirlenen 30 unsurdan 18'ine yer vererek ilk sırada Altın Yunus Çeşme Turistik Tesisler A.Ş. yer almıştır.

BIST' te işlem gören konaklama şirketlerinin 2018 yılı faaliyet raporları incelendiğinde ise Altın Yunus Çeşme Turistik Tesisler A.Ş., ekonomik 4 unsurdan tamamına faaliyet raporunda yer veren tek BIST konaklama şirketi olmuştur. Bu durum çevresel ve sosyal unsurlar için de geçerli olmuştur. Şirket çevresel ve sosyal unsurların tamamına 2018 yılı faaliyet raporunda yer vermese dahi, analiz dahilindeki diğer konaklama şirketlerine kıyasla daha yüksek performans göstermiştir. Gerçekleştirilen faaliyetlerin ISO 9001 Kalite Yönetim Sistemi çerçevesinde gerçekleştirildiğini, çevresel duyarlılık kapsamında Yeşil Yıldız Ödülü'nün bulunduğunu belirten şirket, sürdürülebilirliğin bilincinde olduğunu, bu günün kaynaklarını gelecek nesiller için korumanın gerekliliğini vurgulamıştır. BIST konaklama şirketleri içinde 2018 yılında en düşük performansı toplam 3 unsura yer veren Merit Turizm Yatırım ve İşletme A.Ş. ile Metemtur Otelcilik ve Turizm Şirketleri A.Ş.'nin gösterdiği görülmüştür. Bu şirketler GRI ilkeleri çerçevesinde ekonomik, çevresel ve sosyal bağlamda toplam 46 unsur içinden sadece 3 unsuru karşılamışlardır. Söz konusu şirketler 2018 yılı faaliyet raporlarında çevresel hiçbir unsura yer vermemiştir. Ekonomik ve sosyal faktörler bağlamında ise sadece genel ifadelere yer vermişlerdir. Bu ifadeler ise sürdürülebilirlik bağlamında değerlendirildiklerinde bu şirketlerin oldukça düşük performans sergilediklerini ortaya koymuştur.

BIST konaklama şirketlerinin 2019 yılı faaliyet raporları incelendiğinde, ekonomik, faktörler başlığı altında belirlenen ekonomik unsurların tamamına yer veren tek şirketin yine 2017 ve 2018 yıllarında olduğu gibi yine Altın Yunus Çeşme Turistik Tesisler A.Ş. olduğu gözlemlenmiştir. 2019 yılında çevresel unsurlar bağlamında incelenen şirketlerin en fazla yer verdikleri unsurun ise yine "Genel" olduğu, şirketlerin çevresel duyarlılıkları ile ilgili detaylı bilgilerden ziyade genel bir yargıya yer verdikleri gözlemlenmiştir. 2019 yılında da "biyolojik çeşitlilik ve nakliye unsurları" ile ilgili hiçbir şirket açıklama yapmamış ve raporlarında bu bilgileri kapsayan ifadelere yer vermemişlerdir. 2017 ve 2018 yıllarında olduğu gibi 2019 yılında da çevresel unsurlara raporlarında yüksek oranda yer veren şirket Altın Yunus Çeşme Turistik Tesisler A.Ş. olmuştur. BIST konaklama şirketlerini 2019 yılı faaliyet raporları sosyal unsurlar bağlamında incelenmesi sonucu otuz sosyal unsurdan on dokuzunu karşılayan Altın Yunus Çeşme Turistik Tesisler A.Ş.'nin yine en yüksek performansı gösterdiği gözlemlenmiştir.

Analiz kapsamındaki BIST konaklama şirketlerinin hiçbirinin sürdürülebilirlik raporu yayımlamadıkları gözlemlenmiştir. Bu bulgu söz konusu konaklama şirketleri açısından son derece önemli bir eksiklik olarak saptanmıştır.2017, 2018 ve 2019 yıllarına ait faaliyet raporları analiz edilen konaklama şirketlerinin gerçekleştirdikleri sürdürülebilirlik faaliyetleri ve bu faaliyetlerin raporlanmasıyla ilgili olarak genel bağlamda oldukça düşük performans gösterdikleri ve gerçekleştirilen faaliyetlerin GRI standartları açısından yetersiz olduğu analiz sonucu ortaya konmuştur. Elde edilen bu bulgu Herremans ve diğerleri (2011) araştırmasında Çin ve Hindistan'daki kumarhane otellerinden elde edilen sonuçlarla paralellik göstermektedir. Bu bağlamda Türkiye gibi özellikle ekonomik açıdan gelişmekte olan ülkelerdeki konaklama işletmelerinde sürdürülebilirlikle ilgili farkındalığın tam anlamıyla yaratılamadığını söylemek mümkündür. Bununla birlikte bu ülkelerde hissedar ve kredi kurumlarının sürdürülebilirlikten ziyade daha çok ekonomik kazanç üzerinde yoğunlaştıkları ve şirketleri bu açıdan yönlendirdikleri düşünülmektedir. Bu problemin sadece şirket yöneticilerinin zihinsel değişimiyle değil, bütünsel olarak hissedar ve kreditör gibi piyasa aktörlerinin de ekonomik karla birlikte sürdürülebilirlik faaliyetlerine önem vermeleriyle ortadan kalkabileceği düşünülmektedir.

Konaklama şirketlerinde 2017, 2018 ve 2019 yıllarında ekonomik faktörler bağlamında en fazla yer verilen unsur "ekonomik performans" olurken; "satın alma uygulamaları" en az yer verilen unsur olmuştur. Analiz kapsamındaki konaklama şirketlerinin borsada işlem gören 
şirketler olması nedeniyle ekonomik performans göstergelerinin şeffaflık ilkesinin bir gereği olarak en fazla yayınladıkları ekonomik unsur olduğu düşünülmektedir. Buna karşın bu şirketlerin sunacakları ürün veya hizmetleri gerçekleştirmek için satınalma uygulamalarıyla ilgili daha fazla hususa dikkate alarak sürdürülebilirlik faaliyeti gerçekleştirmeleri gerekmektedir.

Çevresel bağlamda konaklama şirketlerinin en fazla yer verdikleri unsur birçok şirketin çevresel duyarlılığını genel bir ifade ile belirtmiş olması nedeniyle "Genel" olurken, en az yer verilen unsurlar; "biyolojik çeşitlilik ve nakliye" olmuştur. Elde edilen bu bulgu Medrado ve Jackson (2015) ve Karadeniz ve Uzpak (2019) çalışmalarının sonuçlarıyla paralellik gösterdiği söylenebilir. Medrado ve Jackson (2015) çalışmasında, cruise ve yiyecek-içecek şirketlerinin en fazla çevre unsurlarına yönelik raporlama yaptıkları buna karşın otel işletmelerinin ise çevresel unsurlarla ilgili yeterli bir raporlama yapmadıkları saptanmıştır. Karadeniz ve Uzpak (2019) çalışmasında ise otel zincirlerinin ekonomik ve sosyal kategoriye ağırlık verdiği, çevre ile ilgili faaliyetlerini raporlamada ise yetersiz kaldıkları saptanmıştır. Bu açıdan bakıldığında henüz konaklama işletmelerinde diğer turizm işletmelerine göre çevresel farkındalığın tam anlamıyla oluşmadığı söylenebilir. Doğal kaynaklar ve çevre ile doğrudan bağlantılı olan turizm sektöründe sürdürülebilirlik ile ilgili unsurlara bu derece düşük oranda önem verilmesi, sektörün sürekliliği ve kaynakların zarar görmemesi açısından büyük bir eksikliktir. Bu bağlamda konaklama işletmelerinde çevre unsurunun sadece üzerinde söz söylenen bir unsur olmaktan çıkıp, üzerinde düşünülen ve eyleme dönüşen bir kavram haline gelmesi ve sektördeki yatırımcı, hissedar, çalışan ve tüketicinin bu konuda daha fazla konaklama işletmesi yöneticilerini zorlamaları gerekmektedir. Son olarak konaklama şirketlerinin sosyal unsurlar çerçevesinde "istihdam" unsurunun en fazla yer verilen unsur olduğu; "toplum üzerindeki etkilere ilişkin şikayet mekanizması ile müşteri sağlığı ve güvenliği" unsurlarının şirketler arasında en az yer verilen unsurlar olduğu ortaya konmuştur. Turizm sektörünün emek yoğun bir sektör olması nedeniyle istihdam unsurunun konaklama işletmelerinin raporlarında yoğun bir şekilde yer verilmesi doğaldır. Bununla beraber konaklama şirketlerinin şikayet mekanizmalarını daha etkin hale getirmeleri ve gelen şikayetleri yanıtlayarak gerekli düzeltici önlemleri yerine getirmeleri son derece önemlidir.

Gerçekleştirilen araştırmada elde edilen sonuçların BIST'te işlem gören konaklama şirketlerinin sürdürülebilirlik bağlamında göstermiş oldukları ve raporladıkları faaliyetleri ortaya konması ve bu şirketlerin eksikliklerini görmeleri ve bu bağlamda önlemler almaları açısından yararlı olabileceği düşünülmektedir. Ayrıca ilgili literatür incelendiğinde BIST'te işlem gören konaklama şirketlerinin sürdürülebilirlik faaliyetleri ve bu faaliyetlerin raporlanmasına yönelik bir araştırmaya rastlanmadığından araştırmanın bu bağlamda literatüre katkı sağlayacağı düşünülmektedir. Araştırma sonucunda elde edilen bulgular değerlendirilirken, araştırmanın 3 yılı kapsayan faaliyet raporları ile kısıtlı olması, konaklama şirketlerinin ayrıca sürdürülebilirlik raporlarının bulunmamasının göz önünde bulundurulması gerekmektedir. Gelecekte, turizm sektörünü oluşturan diğer turizm şirketlerini de kapsayan ulusal ve uluslararası karşılaştırmalı çalışmaların literatüre katkı sağlayacağı düşünülmektedir. Ayrıca konaklama şirketlerinin sürdürülebilirlik performansı ile finansal performansları arasındaki ilişkinin incelenmesinin de literatüre katkı sağlaması açısından önemli olacağı düşünülmektedir.

\section{Kaynakça}

Anand, S. ve Sen, A. (2000), "Human Development and Economic Sustainability", World Development, 28(12), ss. 2029-2049.

Başar, A.B. ve Başar, M. (2006), "Sosyal Sorumluluk Raporlaması ve Türkiye'deki Durumu", Sosyal Bilimler Dergisi, 6(2), ss. 213-230.

Bayraktutan, Y. ve Uçak, S. (2011), "Ekolojik İktisat ve Kalkınmanın Sürdürülebilirliği”, Akademik Araştırmalar ve Çalışmalar Dergisi, 3(4), ss.17-36.

Borsa İstanbul (2014), "Sürdürülebilirlik Rehberi", http://www.borsaistanbul.com/data/ kilavuzlar/surdurulebilirlik-rehberi.pdf.(01.11.2018). 
Borsa İstanbul (2015), "Borsa İstanbul Sürdürülebilirlik Endeksi Araştırma Metodolojisi", https://www.borsaistanbul.com/endeksler/bist-pay-endeksleri/surdurulebilirlik-endeksi (21.04.2018).

Chapinlı F. S.,Torn, M. S. ve Tateno, M. (1996), "Principles of Ecosystem Sustainability", American Naturalist, 148(6), ss. 1016-1037.

Cıocolu, C. N. (2011), "Integrating Digital Economy and Gren Economy: Opportunities for Sustainable Development", Theoretical and Empirical Researches in Urban Management, 6(1), ss. 33-43.

Ekergil, V. ve Göde, M. Ö. (2017), "Küresel Raporlama Girişimi (GRI) Standartlarına Göre Seçilen Otellerin Sürdürülebilirlik Raporlarının Analizi ve Değerlendirilmesi”, Business and Economics Research Journal, 8(4), ss. 859- 871.

Fınkbeıner, M.,Schau, E. M., Lehmann, A. ve Traverso, M. (2010), "Towards Life Cycle Sustainability Assessment", Sustainability, 2(10), ss. 3309-3322.

Gri-Global Reportinglnitiative G3 (2006), GRI G3 Sustainability Reporting Guidelines Report, https://www.globalreporting.org/information/news-and-press-center/Pages/GRIintroduces-G3-Checklist-to-help-reportingorganizations-.aspx (25.11.2016).

Gri-Global Reportıng InitiativeG4 (2013), GRI G4 Sustainability Reporting Guidelines Report, https://www2.globalreporting.org/ standards/g4/Pages/default.aspx (20.11.2016).

Guıxa, M.,Bonılla-Priego, M. J. ve Font, X. (2018), "The Process of Sustainability Reporting in International Hotel Groups: An Analysis of Stakeholder Inclusiveness, Materiality and Responsiveness", Journal of Sustainable Tourism, 26(7), ss.1063-1084.

Herremans, I., Pyası, N. ve Lu, J. (2011), "The Journey Toward Sustainability Reporting: How Accountable are the Tourism Industries?", Tourism Recreation Research, 36(3), ss. 247257.

Karadeniz, E. ve Uzpak, B.D. (2019), "Dünyada En Yüksek Marka Değerine Sahip Otel Zincirlerinin Sürdürülebilirlik Faaliyetlerinin Küresel Raporlama Girişimi İlkeleri Bağlamında İncelenmesi", Seyahat ve Otel Işsletmeciliği Dergisi, 16(1), ss. 6-20.

Kuşat, N. (2012), "Sürdürülebilir Şirketler İçin Kurumsal Sürdürülebilirlik ve İçsel Unsurları", Afyon Kocatepe Üniversitesi İiBF Dergisi, 14(2), ss. 227-242.

Lıu, Z. (2003), "Sustainable Tourism Development: A Critique", Journal of Sustainable Tourism, 11(6), ss. 459-475.

Medrado, L. ve Jackson, L. A. (2016), "Corporate Nonfinancial Disclosures: An Illuminating Look at the Corporate Social Responsibility and Sustainability Reporting Practices of Hospitality and Tourism Firms", Tourism and Hospitality Research, 16(2), ss.116-132.

Özmehmet, D.E. (2008), "Dünyada ve Türkiye'de Sürdürülebilir Kalkınma Yaklaşımları”, Journal of Yaşar University, 3(12), ss.1853-1876.

Pamukçu, F. (2011), "Finansal Raporlama ile Kamuyu Aydınlatma ve Şeffaflıkta Kurumsal Yönetimin Önemi", Muhasebe ve Finansman Dergisi, 50, ss.133-148.

Şimşek, H. ve Yıldırım, A. (2000), Sosyal Bilimlerde Nitel Araştırma Yöntemleri, Ankara: Seçkin Yayınevi.

Tavşancıl, E. ve Aslan, E. (2001), İçerik Analizi ve Uygulama Örnekleri, İstanbul: Epsilon Yayıncılık.

UNEP (2005), “Annual Evaluation Report”, http://wedocs.unep.org/bitstream/handle/ 20.500.11822/183/UNEP_Anual_Evaluation_Report_2005.pdf?sequence=1\&is. (13.04.2016).

UNWTO (2017), "Tourism and the Sustainable Development Goals-Journey to 2030", https://www.undp.org/content/dam/undp/library/Sustainable\%20Development/UNWTO_U NDP_Tourism\%20and\%20the\%20SDGs.pdf (10.12.2018).

Yükçü, S. ve Kaplanoğlu, E. (2016), "Sürdürülebilir Kalkınmada Finansal Olmayan Raporlamanın Önemi”, Muhasebe Bilim Dünyası Dergisi, 18(1), ss.63-101. 